\title{
Ueber
}

\section{die Hautmuskeln der Vögel, ihre Beziehungen zu den Federfluren und ihre Functionen.}

Von

Franz Helm aus Schöneck i. V.

(Hierzu eine Tafel.)

Muskeln, welche die Haut des Körpers bewegen, treten oft schon in sehr mächtiger Entwicklung bei den wirbellosen Thieren auf, doch dienen sie bei ihnen nie zur ausschliesslichen Bewegung der äusseren Haut, sondern sie sind in vielen Fällen zugleich die wichtigsten Locomotionsorgane. Erst bei den am höchsten organisirten Wesen, den Wirbelthieren, tritt der Fall ein, dass besondere Muskeln sich differenziren, deren alleiniger Zweck die Bewegung der den Körper bedeckenden Haut und ihrer Anhänge ist. Natürlich finden sich derartige Muskeln, je nach der äusseren Bedeckung und der Lebensweise, bei den einzelnen Klassen der eben namhaft gemachten Thiergruppe in verschiedener Ausbildung. Am höchsten differenzirt sind sie bei den Säugethieren und Vögeln. In der vorliegenden Arbeit habe ich den Versuch gemacht, die Hautmuskeln der Vögel, wie sie bei den von mir untersuchten Gliedern der einzelnen Ordnungen auftreten, eingehend zu beschreiben und zugleich ihre Functionen anzugeben. Allerdings muss ich gleich an dieser Stelle betonen, dass ich als Hautmuskeln nur diejenigen betrachtet und in Folge dessen in den Bereich meiner Untersuchungen gezogen habe, die hauptsächlich oder ausschliesslich dazu dienen, Stellen der Haut, welche ganz oder zum Theil mit Federn besetzt sind, also ganze Fluren oder Theile derselben, oder einzelne Federn zu bewegen. Nicht berücksichtigt habe ich daher die Muskeln, welche die Ohröffnungen verengern und erweitern, sowie jene, welche die Augenlider und das Steissbein sammt den Steuerfedern bewegen. Auch den Spanner der vorderen Flughaut habe ich nicht näher untersucht, weil er einerseits kaum als Hautmuskel im eigentlichen Sinne des Wortes angesehen werden kann und auch von keinem Anatomen (wie Meckel und Owen) als solcher betrachtet wird, andererseits auch

Cab. Journ. f. Ornith, XXXII. Jahrg. No. 167 u. 168. Juli u. October 1884. 
mehrfach (wie namentlich von dem zuerst genannten Forscher) bei den verschiedenen Vögeln genau untersucht und sein Verhalten bei den einzelnen Ordnungen beschrieben worden ist. Die vorliegende Arbeit kann daher schon aus diesem Grunde keinen Anspruch auf Vollständigkeit machen. Dazu kommt aber noch der Umstand, dass keineswegs eine so grosse Anzahl Arten untersucht wurden, dass aus dem gefundenen Resultate ein Schluss über die Ausbildung der Hautmuskulatur der einzelnen Vogelordnungen gezogen werden könnte.

Veranlasst wurde ich zu dieser Arbeit durch die Aufforderung meiner hochgeehrten Lehrer, des Herrn Geheimrath Prof. Dr. Leuckart und des Herrn Dr. Marshall. Beide Herren standen mir auch während meiner Untersuchungen mit Rath und That zur Seite, und ich kann desshalb nicht unterlassen, auch an dieser Stelle ihnen meinen innigsten Dank auszusprechen. Namentlich fühle ich mich Herrn Geheimrath Prof. Dr. Leuckart zu ganz besonderem Dank verpflichtet, da er mir einen grossen Theil des zu meinen Untersuchungen nöthigen Materials freundlichst besorgte und auch die kostbarsten und seltensten Vögel wie Goura, Nothura, Palamedea, soweit es in seinen Kräften stand, mir gütigst zur Verfügung stellte.

Obwohl man an jedem Tage die Wirkungen der Hautmuskeln bei den Vögeln beobachten kann, hat sich doch bis jetzt noch kein Beobachter die Mühe genommen, diese Muskeln bei den verschiedenen Vogelordnungen einer genauen Untersuchung zu unterwerfen. Allerdings sind im Laufe dieses Jahrhunderts von verschiedenen Anatomen bei der Beschreibung der gesammten Muskulatur der Vögel auch Hautmuskeln beschrieben worden, aber immer waren es, wie sich aus der folgenden Uebersicht der bis jetzt gelieferten Beschreibungen ergeben wird, nur einzelne Vögel, bei denen man die in Reds stehenden Muskeln näher untersuchte.

Der erste Forscher, der, soviel mir bekannt ist, die Hautmuskeln eines Vogels beschreibt, ist Wiedemann. Er giebt*) neben der Schilderung der Muskulatur des Schwans auch eine Beschreibung: der bei diesem Vogel vorkommenden Hautmuskeln und zählt deren 4 unter den folgenden Namen auf:

Den Hautmuskel des Halses (Subcutane us colli). " dreieckigen Kehlmuskel (Triangularis juguli). " Bauchhautmuskel (Subcutaneus abdominalis).

" Brusthautmuskel (Subcutaneus thoracicus).

Die Schilderung dieser Muskeln lautet folgendermassen:

„Der Hautmuskel des Halses (Subcutaneus colli) fängt schmal dicht über der äusseren Ohröffnung an, geht breiter.werdend über das hintere Seitenzungenbein mit schräg einwärts steigenden Fasern hin, verbindet sich an der vorderen Seite des Halses mit

*) Archiv für Zoologie und Zootomie. Bd. II Stück 2 p. 69-70. 
dem der anderen Seite und steigt so, eine weite Muskelscheide bildend, am ganzen Halse hinab. Er sträubt die Federn des Halses und spannt die Haut des Halses bei den verschiedenen Bewegungen desselben an.

Der dreieckige Kehlhautmuskel (Triangularis juguli), ein dünner platter Muskel, dessen Spitze am hintersten Theile des Unterkiefers befestigt ist. Die innen liegende Grundfläche des Dreiecks geht an eine sehr dïnne Flechsenhaut, welche mitten auf den ersten Ringen der Luftröhre liegt und diesen beiden Muskeln von jeder Seite gemeinschaftlich ist. Nach hinten liegen beide Grundflächen dieser Muskeln etwas näher zusammen als nach vorn. Er scheint durch sein Zusammenziehen, ausser der Anspannung der Haut, auch die Luftröhre zuriuckdrücken zu können.

Der Bauchhautmuskel (Subcutaneus abdominalis) geht als ein plattes, von der Haut der Gegend des Knies mit 2 sehr abgerundeten kurzen Enden anfangendes Bündel nach unten und hinten, wo er etwas breiter werdend immer unter der Haut über den äusseren schiefen Bauchmuskel nach dem breit abgerundeten Ende des "Schambeins" hinläuft und sich an dessen vorderen Rande mit einer breiten Flechsenhaut befestigt. Sträubt die Seitenfedern des Bauches.

Der Brusthautmuskel (Subeutaneus thoracicus) geht von der Gegend über und vor dem Knie unter der Haut bis unter den hintern Rand des grossen Brustmuskels, da, wo sich dieser am Oberarm befestigt. Er steht mit der Flechse des Brustmuskels in Verbindung und ist lang, platt und schmal. Sträubt die Federn an der Seite der Brust."

Den Spanner der hinteren Flughaut (Tensor membranae alae posterioris) zählt demnach dieser Forscher nicht mit zu den Hautmuskeln. Er belegt mit diesem Namen, wie ich glaube erwähnen zu müssen, 2 getrennt entspringende und verlaufende Muskelpartien, die nur an ihrer Insertionsstelle neben einander zu liegen kommen. Die eine derselben entspringt „mit einer platten Flechse von der 8. und 7. Rippe", die andere hingegen, welche er "gleichsam als eine Portion" des L a tis s im us d or s i betrachtet, kommt von dem vordern Rande des Os ilium.

Der nächste Forscher, der der Hautmuskeln der Vögel Erwähnung thut und auf sie näher eingeht, ist Tiedemann. Er beschreibt*) die 5 folgenden, nach seiner Angabe allen Vögeln zukommenden Muskeln:

Den Stirn- und Hinterhauptmuskel (M. frontalis et oc cipitalis).

Den Hautmuskel des Halses (Subeutaneus colli Wied.).

Den dreieckigen Kehlmuskel ( $\mathrm{Tri}$ angularis juguli Wiedem.).

*) Anatomie und Naturgeschichte der Vögel. B. II p. 133. 
Den Brusthautmuskel (Subcutaneus thoracis). Wiedem.).

Den Bauchhautmuskel (Subcutaneus abdominalis

Für 4 seiner Muskeln hat er, wie sich aus dem Vorstehenden ergiebt, die Namen, die Wiedemann den Hautmuskeln des Schwans gegeben hat, beibehalten, ja er hat sogar die Beschreibung, wie sie der erste Forscher für die bei dem eben namhaft gemachten Vogel vorkommenden Muskeln giebt, dem Wortlaute nach in seine Beschreibung der Hautmuskeln, die allen Vögeln zukommen sollen aufgenommen, vindicirt demnach allen Vögeln Hautmuskeln von derselben Form, allerdings, wie sich im Laufe dieser Arbeit ergeben wird, keineswegs mit vollem Rechte, der 5. Muskel, den er als Stirn- und Hinterhauptsmuskel beschreibt, ist eigentlich aus 2 Theilen zusammengesetzt. Der eine, den er als Stirnmuskel bezeichnet, entspringt nach seiner Beschreibang von der Wurzel des Schnabels, ist mit Sehnenfasern verwebt, läuft nach hinten und vereinigt sich mit dem andern Theil, dem Hinterhauptmuskel, welcher von der Querleiste des Os occipitale und vom Hautmuskel des Halses kommt. Besonders stark soll dieser Muskel sein bei den Vögeln mit einem Federbusch auf dem Kopfe, namentlich aber beim Wiedehopf.

Den Spanner der hinteren Flughaut betrachtet er ebenso wenig wie Wiedemann als einen Hautmuskel. Was er mit diesem Namen bezeichnet ist übrigens nur die Partie, die von dem vordern Rande des Os ili u m kommt, während er den Muskel, welchen die neueren Anatomen als den eigentlichen Spanner der hinteren Flughaut ansehen, als eine Verstärkung des von ihm mit diesem Namen bezeichneten Muskels auffasst. Anderer Meinung über die Stellung: des Spanners der hinteren Flughaut ist dagegen der nächste hier in Betracht kommende Forscher, Meckel. Er sagt nach der Beendigung der Schilderung des Spanners der vorderen Flughaut bei den verschiedenen Vögeln über den hier in Frage kommenden Muskel Folgendes: *)

„Nur den Spanner der vorderen Flughaut betrachte ich hier, der Spanner der hinteren Flughaut scheint mir richtiger in der Lehre von den Hautmuskeln abgehandelt $\mathrm{zu}$ werden, indem er zwar von Knochen entspringt, sich aber nicht unmittelbar an andere, von ihm bewegte setzt."

Er rechnet also diesen Muskel zu den Hautmuskeln. Nirgends in seinem ausführlichen Werke der vergl. Anatomie kommt er aber dann wieder auf die Hantmuskeln zurïck. D'Alton, der nach Meckel zu erwähnende Forscher, neigt sich wieder der Ansicht Wiedemann's zu und rechnet den Spanner der hinteren Flughaut nicht zu den Hautmuskeln. Er beschreibt diesen Muskel in seiner Abhandlung: „De strigum musculis commentatio**) bei den von

*) System der vergl. Anatomie. 3. Theil p. 343 .
*) p. 19 . 
ilhm untersuchten Vögeln, den Eulen, und lässt ihn ebenfalls aus 2 Theilen sich zusammensetzen, von denen der eine von der 4., 5 . und 6. untersten Rippe, der andere hingegen von der schon mehrmals genannten Stelle des Os ilium entspringt. Als eigentliche Hautmuskeln zählt er bei Strix decussata $5 *$ ) auf, von denen 3 denjenigen entsprechen, die Wiedemann als Subcutan e us colli, Subcutaneus abdominalis und Subcutaneus thoraci cu s bezeichnet. Der 4. Muskel, welchen D'Alton ebenfalls mit einem Namen von Wiedemann belegt und den er als Triang $u-$ laris juguli bezeichnet, entspricht jedoch keineswegs dem Muskel, den der letztere Forscher darunter verstanden hat. Aus der wörtlich angeführten Beschreibung dieses Muskels von Wiedemann ist ersichtlich, dass Letzterer als Triangularis juguli den Muskel bezeichnet, der vom hintersten Ende des Unterkiefers entspringt und sich unter der Haut, die die Kehle bedeckt, ausbreitet. D'Alton aber beschreibt unter dem schon mehrmals erwähnten Namen einen Muskel, dessen Fasern nach seiner Angabe bei Strix decussata von dem Ligament, das sich zwischen Furcula und, wie er schreibt, Clavicula (wahrscheinlich soll es heissen Coracoid) ausspannt, entspringen und sich strahlenförmig an den Seiten des Halses zur Kehle und zum Nacken erstrecken sollen. Als 5. Hautmuskel, dem er aber keinen besonderen Namen gegeben hat, ist schliesslich noch ein langer flacher Muskel hinzugefügt, welcher auf jeder Körperseite von dem unteren schrägen Eortsatz des 4 . Halswirbels kommt, nach hinten verläuft und nach Angabe des Autors den Hals entweder zusammenzieht oder die Haut desselben hin und her bewegt.

Fast gleichzeitig mit der schon angeführten Abhandlung über die Muskulatur der Eulen von D'Alton erschien auch das Werk eines andern Forschers, der gleichfalls auf die Hautmuskeln der Vögel näher eingeht, es ist dies das "System der Pterylographie" von Chr. Ludwig Nitzsch. Bei der Schilderung der verschiedenen Arten von Federn**) erwähnt dieser Forscher auch Hautmuskeln und zwar diejenigen, die sich zwischen die einzelnen Conturfedern ausspannen. Er giebt die Zahl dieser Muskeln, welche an jede einzelne Feder gehen, auf 4 an, bemerkt aber dabei, dass die Zahl gelegentlich auch auf 5 erhöht würde. Den Zweck der in Rede stehenden Muskeln sieht er in dem Sträuben und Anlegen der Conturfedern.

Unter den neueren Anatomen sind es nur Owen und Magnus, die in ihren Werken auf die Hautmuskeln der Vögel näher eingehen. Der erste Forscher giebt eine ausführliche Beschreibung: der Hautmuskeln, wie er sie beim Aptery $x$ gefunden hat.**) Er führt bei diesem Vogel folgende Muskeln auf:

*) De strigum musculis commentatio, p. 1 u. 2.

**) p. 17.

***) Comparative Anatomie and Physiology of Vertebrates. Vol. II p. 109-112. 
Den Constrictor colli.

"Sterno-cervicalis.

"Sterno-maxillaris.

"Dermo-transversalis.

"Dermo-spinalis.

" Dermo-iliacus.

"Dermo-costalis.

" Dermo-ulnaris und

"Dermo-humeralis. massen:

Die Beschreibung dieser Muskeln lautet ungefähr folgender-

„Der Constrictor colli besteht aus 2 verschiedenen Muskellagen; die Fasern der einen, die unmittelbar unter der äusseren Haut liegt, laufen von der Mittellinie des Hinterhalses schräg nach der Mittellinie des Vorderhalses und bilden dort eine Naht. Die Fasern der anderen Partie hingegen entspringen von dem Os occipitale, laufen nach hinten und sind mit den Fasern der ersten Partie fest verbunden. Beide Portionen bilden eine Scheide, die am stärksten an der Ursprungsstelle der zweiten Lage ist und die den ganzen Hals umgiebt. Der Constrictor colli dient dazu, die Haut des Halses zu falten, die Halsfedern zu sträuben und, in Gemeinschaft mit dem folgenden, dieselben zu schütteln.

Der Sterno-cervicalis entspringt von dem hinteren gekrümmtẹ Fortsatz des Sternums und von der schwertförmigen Verlängerung und Mittellinie der äussern und hinteren Seite desselben Knochens. Seine Fasern laufen vor- und aufwärts und inseriren sich an die Mittellinie der Haut des Hinterhalses. Er dient dazu, die Haut des Hinterhalses zurïckzuziehen und den Theil, der den Hinterhals bedeckt, zu spannen. Wenn aber sowohl die ganze Haut des Halses als auch der Theil derselben, welcher den Hinterhals bedeckt, fixirt ist, so wird dieser Muskel das Sternum bewegen und auf diese Weise bei der Athmung: thätig sein.

Der Sterno-maxillaris scheint auf den ersten Blick ein Theil des vorigen zu sein; aber er ist hinreichend differenzirt, um einen besonderen Namen und eine besondere Beschreibung zu verdienen. Er entspringt von dem vorderen Theile der Mittellinie des Sternums, läuft vorwärts und theilt sich in 2 gleiche Partien, die sich an die Haut, welche die Kehle und den Winkel des Unterkiefers bedeckt, inseriren. Er zieht den vorderen Theil der Halshaut und zugleich den Kopf nach hinten.

Der Dermo-transversalis entspringt von den unteren schrägen Fortsätzen des sechsten bis zwölften Halswirbels; seine Fasern laufen schief nach unten und hinten und inseriren sich an die Mittellinie des Hinterhalses.

Der Dermo-spinalis entspringt von den oberen Fortsätzen 
der 3 vorderen Rückenwirbel und inserirt sich an die Haut, welche die Scapula bedeckt.

Der Dermo-iliac us entspringt von dem vorderen Rand des 0 s ilium, läuft nach vorne und inserirt sich ebenfalls an die Haut, die die Seapula bedeckt.

Der Dermo-costalis entspringt von den Anhängen der siebenten und achten Rippe, läuft vorwärts, vereinigt sich mit dem Dermo-iliacus und inserirt sich an derselben Stelle wie der letztere. Die 3 zuletzt beschriebenen Muskeln sind breit und dünn, aber wohl von einander gesondert, sie wirken durch die Haut, an die sie sich inseriren, auf den Flügel in demselben Maasse ein, als die eigentlichen verkümmerten Flugmuskeln.

Der Dermo-ulnaris ist ein schmaler Muskel, der unter dem Dermo-costalis entspringt und sich an den Elbogen inserirt. Er hebt den Flügel.

Der Dermo-humeralis entspringt von dem Hauptgewebe des Abdomens, läuft auf- und vorwärts und inserirt sich an den Humerus."

Unter diesen Muskeln, die Owen beim Apteryx beschreibt, entsprechen einige denjenigen, die Wiedemann beim Schwan anführt. Der Theil des Constrictor colli, der beim Apteryx vom Os occipitale kommt, ist kein anderer, als der Subcutaneus colli Wiedemann's. Ebenso entspricht der Dermo-costalis und der Dermo-iliacus den beiden Theilen des Tensor membranae alae posterioris des eben genannten Forschers, und endlich ist eine kleine Muskellage, die beim Apteryx von der Aussenseite des hinteren Theils des Unterkiefers entspringt und sich an die Haut der Kehle inserirt, vou Owen aber mit keinem besonderen Namen belegt wird, dem Muskel, welchen Wiedemann als Triangularis juguli bezeichnet, gleichzustellen.

Der neben Owen namhaft gemachte Forscher, Magnus, betrachtet*) ebenso wie Meckel den Spanner der hinteren Flughaut (Tensor cutis brachialis posterioris), der dem Dermocostalis Owen's entspricht, als Hautmuskel und lässt ihn von den 2-3 mittleren Rippen mit mehreren Köpfen, deren Zahl bis auf 3 steigen kann, entspringen. Ausserdem erwähnt er in seinen „Physiologisch-anatomischen Studien über die Brust- und Bauchmuskeln der Vögel" noch 2 Muskelbündel, die an der Brust vorkommen sollen und die er als Hautmuskeln betrachtet. Den Ursprung und Verlauf derselben schildert er mit folgenden Worten **):

„Das eine Bündel entspringt parallel dem unteren Rande des Pectoralis vom $\mathrm{H} \mathrm{u} \mathrm{merus} \mathrm{und} \mathrm{verläuft} \mathrm{zur} \mathrm{Brusthaut,} \mathrm{während}$ das andere vom 0 s coracoideum als selbstständiger Muskel-

*) Anatomisch-physiologische Studien über die Brust- und Bauchmuskeln der Vögel, p. 223-224.

**) Ebendaselbst, p. 214. 
bauch entspringend vom Pectoralis Verstärkungsfasern bezieht und zur Armhaut geht."

Weiter sagt er über die Ausbildung der beiden Bündel noch Folgendes :

"Das erstere Bündel habe ich besonders scharf bei Picus ausgeprägt gefunden, während das andere sich bei den Fringillae recht entwickelt zeigt."

Die der Reihe nach aufgezählten Forscher sind es also, die bis jetzt specielle Beschreibungen der Hautmuskeln der Vögel veröffentlicht haben und daher bei der speciellen Schilderung der in Frage kommenden Muskeln bei den einzelnen Vogelordnungen von mir berücksichtigt werden müssen. Ehe ich aber zu der Darstellung meiner Befunde übergehe, glaube ich, ist es nöthig, einige Bemerkungen über die Methode der Untersuchung der Hautmuskeln, über die Bezeichnung der bei der speciellen $\mathrm{Be}-$ schreibung vorkommenden Muskeln, Fluren und Raine und endlich einige allgemeine Bemerkungen über die Hautmuskeln selbst vorauszuschicken.

\section{Methode der Untersuchung der Hautmuskeln.}

Die Untersuchung der Hautmuskulatur der Vögel ist, wenn man nach der im Folgenden angegebenen Methode verfährt und im Abbalgen der Vögel einige Fertigkeit besitzt, im Grossen und Ganzen mit keinen bedeutenden Schwierigkeiten verknüpft. Am besten kommt man zum Ziele, wenn man die Vögel regelrecht abbalgt; die Hautmuskeln sind meist fest mit der Haut verbunden und bleiben desshalb an ihr haften. Natürlich müssen die Muskeln, die von Skelettstücken entspringen, beim Abbalgen kurz hinter ihrer Ursprungsstelle abgeschnitten werden. Je nachdem man die Hautmuskeln der vordern oder hintern Körperseite untersuchen will, muss man mit dem Abbalgen auf dem Rücken oder an der Brust beginnen. Die Haut des Halses und Kopfes zieht sich meist ohne Schwierigkeit ab und braucht daher nicht aufgeschnitten zu werden, wenn der erstere nicht zu schwach und der letztere nicht zu dick ist. Tritt aber dieser Fall ein, so ist es gerathen, die Haut an der Seite der genannten Körperstellen aufzuschneiden; man ist wenigstens dann in der Lage, den vollständigen Verlauf der Hautmuskeln auf einer Seite studiren zu können.

Am meisten empfiehlt es sich, die Vögel frisch zu untersuchen, und ich habe dies, soweit es möglich war, stets gethan. Allerding's ist es nicht in allen Fällen ausführbar, weil die Erlangung des zur Untersuchung nothwendigen Materials zu oft vom Zufall abhängt. Ist man daher genöthigt, Vögel für spätere Untersuchungen aufzubewahren, so thut man gut, bevor man sie in $60-70 \%$ Alkohol bringt, durch einen Schnitt die Bauchhöhle zu öffnen und die Eingeweide herauszunehmen; noch empfehlenswerther aber ist es, die Vögel abzubalgen und dann Haut und 
Körper in Alkohol von obiger Stärke aufzubewahren. Dies letztere Verfahren, wenn irgend möglich, einzuschlagen ist geradezu geboten bei den fetten Sing- und Sumpfrögeln, überhaupt bei allen Vögeln, die ein leicht flüssig werdendes Fett besitzen. Denn wenn man diese Vögel auch in ziemlich starkem Alkohol längere Zeit, ohne sie abzubalgen, aufbewahrt, so nimmt das Fett eine schmierige Beschaffenheit an, wirkt nachtheilig auf die Hautmuskeln ein und erschwert dadurch die Untersuchung derselben ungemein. Das der Haut anhaftende Fett entfernt man ebenfalls am besten von dem frisch abgezogenen Balg. Der grösste Theil lässt sich mit Scalpell und Pincette beseitigen, der übrige dagegen durch Behandeln der Haut mit Benzin entfernen. Obwohl an den so behandelten fetten und an den frischen nicht fetten Bälgen der Verlauf der einzelnen Muskeln erkennbar ist, genügt die bisherige Behandlung doch keineswegs, wenn es sich darum handelt, die letzten Endigungen der Muskelbündel und, wie am Halse, den Verlauf der Fasern der verschiedenen Schichten näher zu studiren. Um dies zu ermöglichen, brachte ich die Bälge, je nach ihrer Grösse und Beschaffenheit, einen oder mehrere Tage lang in Wasser oder, was practischer ist und sich sehr empfiehlt, wenn man die Bälge behufs späterer Controle aufbewahren will, in $30-40 \%$ Alkohol. Wendet man die letztere Methode an, so ist begreiflicherweise eine relativ längere Berührung der Haut mit der Flüssigkeit nöthig, wenn derselbe Erfolg erzielt werden soll. In dem einen wie in dem anderen Fall aber ist es zuerst das der Haut anhaftende Bindegewebe, das von der Flüssigkeit afficirt wird; seine Verbindung mit der Haut wird gelockert, so dass es sich unter Wasser, wenn man den richtigen Zeitpunkt, den man bald durch Probiren findet, nicht versäumt hat, leicht ablösen lässt. Diese Behandlung der Haut wird gewöhnlich hinreichend sein, um den Verlauf und die Endigungen der Muskeln am ganzen Körper mit Ausnahme am Halse, an dem, wie schon erwähnt, 2 oder sogar in den meisten Fällen 3 Muskelschichten über einander lagern, erkennbar zu machen. Um auch an der eben genannten Körperstelle die untersten Muskellagen der Untersuchung zugänglich $\mathrm{zu}$ machen, brachte ich den Balg noch einige Tage in die eine oder andere schon erwähnte Flüssigkeit. Alsdann zog sich die unterste, d. h. die der Körpermuskulatur direct aufliegende Hautmuskelschicht unter Wasser ebenfalls ab, und ich war im Stande, den Verlauf der Fasern der zweiten Muskelschichte und meist auch die Zahl der Muskeln, die sich an die einzelnen Federn behufs deren Bewegung inseriren, mit Leichtigkeit, bei grossen Bälgen mit unbewaffneten Augen, bei kleinen dagegen mit der Lupe zu erkennen.

Die Untersuchungen selbst wurden, wie eben bemerkt, entweder mit den blossen Augen oder mit der Lupe gemacht; nur wenn es sich darum handelte, zu unterscheiden, ob man Muskelfasern oder Bindegewebe vor sich habe, wurde das Mikroskop 
und das gewöhnliche Reagenz zum Erkennbarmachen der Muskeln, die Essigsäure, zu Hülfe genommen.

\section{Benennung der Muskeln, Fluren und Raine.}

Was die Benennung der Muskeln anbetrifft, so habe ich die bei den einzelnen Ordnungen vorkommenden Hautmuskeln, so weit es anging, mit denjenigen Namen belegt, die schon die in der Einleitung zu dieser Arbeit namhaft gemachten Forscher in die Wissenschaft eingefiihrt haben. Es sind demnach theils die Namen von Wiedemann und Tiedemann, theils auch diejenigen, welche Owen bei der Beschreibung der Hautmuskeln des Apteryx gebraucht hat, wieder benïtzt worden. Die Nomenclatur des Letzteren ist freilich nur in so weit benutzt worden, als sie Muskeln betrifft, welche von den ersten beiden Forschern nicht erwähnt werden. Den Spanner der hinteren Flughaut, den, wie schon an anderer Stelle betont ist, Magnus und Owen und vor ihnen auch Meckel in seinem „System der vergl. Anatomie" zu den Hautmuskeln rechnen, werde auch ich als solchen betrachten und desshalb im Laufe dieser Abhandlung auf ihn näher zu sprechen kommen. Doch will ich gleich an dieser Stelle bemerken, dass ich, dem Beispiele Owen's und Magnus folgend, mit dem Namen "Spanner der hinteren Flughaut" oder, wie ihn Magnus bezeichnet," Tensor cutis brachialis posterioris, nur die Muskelpartie belegen werde, die ihren Ursprung von den Rippen nimmt. Den Theil hingegen, der vom vordern Rande des Os ilium oder, wie es manchmal der Fall ist, von den oberen Fortsätzen der letzten Brustwirbel entspringt und sich neben den Spanner der hintern Flughaut an die Haut inserirt, werde ich dagegen, wie dies Owen gethan hat, mit „Dermo-iliacus" bezeichnen. Auch halte ich es für rathsam, den. Namen "Constrictor colli" mit dem, wie ebenfalls in der Einleitung schon dargelegt wurde, Owen die beiden am Halse auftretenden Muskelschichten, von denen die Fasern der einen von vorne nach hinten, die der anderen dagegen rings um den Hals verlaufen, bezeichnet hat, für die bei allen von mir untersuchten Vögeln am Halse sich findenden beiden Muskellagen $\mathrm{zu}$ gebrauchen, weil derselbe die Function, die die beiden Muskelschichten gemeinschaftlich ausüben, am prägnantesten auszudrücken scheint. Bei der Beschreibung des Verbreitungsgebietes der beiden Schichten werde ich auch den Namen „S u bcu ta n e u s colli“, den Wiedemann der obersten Schicht, d. h. derjenigen, die an der abgebalgten Haut zuerst in die Augen fällt, gegeben, gebrauchen und auf diese Weise beiden Forschern gerecht werden. Bei der Beschreibung der Muskeln, welche die in Frage kommenden Forscher mit verschiedenen Namen belegt haben, werde ich die ältere Bezeichnung an die erste Stelle und den Namen, welchen spätere Forscher ihnen beigelegt haben, an zweite Stelle setzen Muskeln endlich, für die bis jetzt kein Name vorhanden ist, werde ich nach demselben Principe wie Owen benennen. Die Namen 
der Federfluren und Raine sind dieselben, welche Nitzsch in seinem „System der Pterylographie" aufgestellt hat.

\section{Allgemeine Bemerkungen iiber die Hantmuskeln der Vögel.}

Bei allen von mir untersuchten Vögeln fand ich die Hautmuskeln nach 2, nur sehr wenig Ausnahmen erleidenden Principien angeordnet. Die nach dem einen Princip angelegten Muskeln verlaufen in der Art, dass sie entweder ganz oder zum Theil von den Fluren, zu deren Bewegung sie dienen, bedeckt werden, oder sie kommen an die Seiten derselben zu liegen und sind dann ebenso wie diejenigen, die unter den Fluren verlaufen, durch Bindegewebe fest mit denselben verbunden. Contrahiren sich diese Muskeln, so falten sie die Haut und sträuben dadurch die in ibr steckenden Federn. Die Muskeln hingegen, die nach dem zweiten Princip angeordnet sind, inseriren sich nur an das eine Ende oder an die Seite der Flur und würden, falls sie sich contrahirten, in keinem Falle die Federn derselben zum Sträuben bringen, wenn nicht, wie ich glaube, folgende Einrichtung getroffen wäre. W'ie Nitzsch schon in seiner „Pterylographie“ ausführlich bei der Beschreibung der Fluren der Schwimmvögel erörtert*), stecken alle Conturfedern mit Ausnahme der Schwung- und Steuerfedern nicht senkrecht in der Haut, sondern unter einem bald spitzeren bald stumpferen Winkel, dessen beide Schenkel nach hinten verlaufen. Die Muskeln nun, die nach dem zweiten Princip angelegt sind, laufen fast ohne Ausnahme von hinten nach vorne und es scheint mir dadurch, auf Grund der eben namhaft gemachten Stellung der Federn, um so eher möglich, als meist auch an das andere Ende der betreffenden Flur sich ein Muskel ansetzt, der von vorne nach hinten verläuft, dass sie gleichfalls ein Sträuben derselben bewirken können, allerdings vielleicht in geringerem Masse als die nach dem ersten Princip verlaufenden. Nach ihrer Ursprungs- und Insertionsstelle lassen sich die bei allen von mir untersuchten Vögeln vorkommenden Hautmuskeln in 2 Gruppen theilen, nämlich in:

1) Solche, die von einem Skelettstück entspringen und entweder nach ihrer Insertion an die Haut daselbst endigen, oder mit der Haut nur eine Strecke lang eine innige Verbindung eingehen, dann aber diese lösen und sich an ein Skelettstiick inseriren.

2) Solche, welểhe von keinem Skelettstïck entspringen, sondern sich nur zwischen 2 Stellen der äusseren Haut ausspannen.

Die erste Gruppe umfasst den grössten Theil der bei den Vögeln vorkommenden Hautmuskeln, nur dass dieselben bald nach dem einen bald nach dem andern Princip verlaufen. Gleiches ist der Fall bei der zweiten Gruppe. Sie umfasst ebenfalls Muskeln, die nach den beiden oben erörterten Principien angelegt

*) p. 203. 
sind, enthält aber nur wenig Muskeln, die allen Vögeln zukommen, dagegen gehören $\mathrm{zu}$ ihr diejenigen, welche nur bei der einen oder anderen Ordnung auftreten.

Was nun endlich die Ausbildung der Hautmuskeln bei den auf verschiedenen Altersstufen stehenden Individuen anbetrifft, so habe ich bei jungen $d$. h. solchen, die ihr vollständiges Federkleid besassen, und alten stets dieselben Muskeln ausgebildet gefunden; doch scheint trotzdem das Alter nicht ohne Einfluss auf die Entwicklung der einzelnen Muskeln selbst zu sein. Ich fand nämlich bei der Untersuchung verschieden alter Exemplare von Crex pratensis, Gallus domesticus, Columba domestica, Corvus corone und Corvus pica, dass bei alten Individuen die Muskulatur viel kräftiger entwickelt war als bei jungen. Namentlich schien mir die ungleiche Ausbildung den Constrictor colli, den Dermo iliacus und den Subcutaneus abdominalis zu treffen.

\section{Specielle Beschreibung der Hautmuskulatur der einzelnen Vogelordnungen.}

A. Muskeln, die an einzelne Federn sich inseriren. Ehe ich die besonders differenzirten Muskeln, die an die einzelnen Federfluren gehen, einer speciellen Beschreibung unterwerfe, halte ich es für geboten, die Muskeln, die an die einzelnen Federn behufs deren Bewegung sich inseriren, näher ins Auge zu fassen. Der Grund, der mich dazu veranlasst, wird sich aus den folgenden Thatsachen ergeben. Bei allen von mir untersuchten Vögeln fand ich fast, wie ja auch nach den Angaben, die Nitzsch über diesen Gegenstand gemacht hat, nicht anders zu erwarten war, das gleiche Verhalten der in Frage kommenden Muskeln, und es würde daher bei der Schilderung der Hautmuskeln der einzelnen Ordnungen nur zu Wiederholungen führen, die ich so viel als möglich vermeiden möchte, wenn ich nicht den hier ins Auge gefassten Weg einschlüge. Aus diesem Grunde lasse ich jetzt die Schilderung der in Rede stehenden Muskeln folgen, wie sie bei allen von mir uutersuchten Vögeln auftreten, und werde dann bei der speciellen Beschreibung der Hautmuskeln der einzelnen Ordnungen nur auf die etwaigen Besonderheiten zu sprechen kommen.

Alle Conturfedern, mit Ausnahme der Schwung- und Steuerfedern, sind mit besonderen Muskeln ausgestattet, deren jeder sich zwischen 2 benachbarten Federn ausspannt. In der Regel sind es, wie Nitzsch in seiner Pterylographie*) schon betont, 4 Muskeln, die sich an die einzelnen Federn inseriren und $\mathrm{zu}$ den benachbarten verlaufen. Je nach der gegenseitigen Stellung der Federn bilden die an sie sich heftenden Muskeln bald Quadrate bald Rechtecke oder Rhomben. Nur in Ausnahmefällen, auf die, wie

*) p. 17. 
schon erwähnt, an anderer Stelle näher eingegangen werden soll, wird die Zahl 4 auf 6 erhöht und dann bilden die neu hinzukommenden Muskeln in jedem Viereck eine Diagonale. Seltener als 6 inseriren sich, wie Nitzsch angiebt, 5 Muskeln an eine Feder, nämlich nur an diejenigen, die am Rande der Strecke stehen, innerhalb deren 6 an jede einzelne Feder gehen. Die in Rede stehenden Muskelu scheinen, nach meinen Untersuchungen, je nach der Grösse der Conturfedern und der Häufigkeit der Bewegung derselben, bald stärker bald schwächer entwickelt zu sein. Relativ am stärksten fand ich sie bei den von mir untersuchten Vögeln stets an denjenigen Körperstellen ausgebildet, die mit keinem besonders differenzirten Hautmuskel ausgestattet waren, deren Federn aber häufig aufgerichtet werden. In sehr ausgeprägtem Masse beobachtete ich diese Erscheinung an den Federn der Stirn und des Vorderhauptes bei den Passeres. In der Regel liegen die Fasern der einzelnen Muskeln, die sich zwischen 2 Federn ausspannen, dicht neben einander und bilden einen förmlichen Strang, nur in einigen Fällen, welche gleich namhaft gemacht werden sollen, fand ich ein etwas anderes Verhalten. Bei einem alten Exemplar von Crex pratensis bildeten die Muskeln, die sich an die auf dem hinteren Theil des Rumpfseitenrains befindlichen Dunen inserirten, keine Stränge, sondern ihre Fasern divergirten stark bogenförmig, so dass man auf den ersten Blick glauben konnte, eine förmliche Muskellage vor sich zu haben. Auch bei Palamedea chavaria beobachtete ich ein ähnliches Verhalten an jenen Muskeln, die an die Dunen sich inserirten, doch nicht in so ausgeprägtem Masse als bei Crex. Ich werde bei der Beschreibung der Hautmuskulatur dieses merkwürdigen und interesșanten Vogels noch einmal auf die eben erwähnte Erscheinung zu sprechen kommen.

Was die Dunen betreffs ihrer Ausrïstung mit Muskeln anbetrifft, so kann ich die Angaben, die Nitzsch darüber macht, im Grossen und Ganzen nur bestätigen. Dieser Forscher giebt nämlich als Unterscheidungsmerkmal zwischen den eben genannten Federn und den Conturfedern die Erscheinung an, dass die letzteren stets mit besonderen zu ihrer Bewegung dienenden Muskeln ausgestattet sind, den ersteren hingegen derartige Muskeln stets fehlen. Auch ich fand bei den von mir untersuchten Vögeln, mit Ausnahme der 2 soeben namhaft gemachten Fälle, keine Muskeln, die sich zwischen Dunen ausspannten. Die Wirkung, die diese Muskeln ausüben, wird, wie Nitzsch ebenfalls schon in seiner Pterylographie erwähnt, in dem Sträuben und Niederlegen der Conturfedern bestehen. Sie werden demnach wohl in den meisten Fällen sich gleichzeitig mit den besonders differenzirten Hautmuskeln, welche an die einzelnen Fluren sich inseriren, contrahiren und auf diese Weise die letzteren unterstïtzen. 
B. Specielle Beschreibung der Muskeln der einzelnen Vogelordnungen, welche an Federfluren sich inseriren.

Nach diesen Betrachtungen, die ich glaubte vorausschicken zu müssen, gehe ich zur Schilderung der Hautmuskeln, wie ich sie bei den von mir untersuchten Mitgliedern der einzelnen Ordnungen gefunden habe, selbst über und beginne, da ich die Eintheilung der Vögel, die Claus in seinem "Lehrbuch der Zoologie“ angiebt, befolgen werde, mit den

\section{Natatores, den Schwimmvögeln.}

Von den Mitgliedern dieser Ordnung habe ich untersucht: Anas clangula, Harelda glacialis, Mergus merganser und z. T. auch Anser domesticus, Anas domestica, Colymbus glacialis und Cereopsis Novae-Hollandiae.

Wiedemann beschreibt, wie aus der Einleitung zu dieser Arbeit ersichtlich ist, bei einem Mitgliede dieser Ordnung, bei dem Schwan, ausser dem Spanner der hinteren Flughaut, den er nicht $\mathrm{zu}$ den Hautmuskeln rechnet, 4 dergleichen Muskeln. Obwohl ich nicht im Stande war, diese Angaben auf ihre Richtigkeit durch Präpariren eines Schwanes zu prüfen, so glaube ich doch aus der Uebereinstimmung der Lebensweise und der Federfluren des in Betracht kommenden Vogels mit denen der Enten und Gänse und aus dem Umstande, dass gerade bei den verschiedenen Arten von Schwimmvögeln, die ich untersuchte, die Hautmuskeln fast stets in derselben Weise entwickelt waren, schliessen zu dürfen, dass auch beim Schwan die in Frage kommenden Muskeln in der Form wie bei den übrigen von mir untersuchten Gliedern dieser Ordnung entwickelt seien.

Ich fand bei den von mir untersuchten Schwimmvögeln folgende Hautmuskeln:

Den Constrictor colli Owen.

"Triangularis juguli Wiedemann.

"Dermo-transversalis Owen.

"Subcutaneus thoracicus Wiedemann.

"Dermo-spinalis Owen.

"Dermo-iliacus Owen.

" Tensor cutis brachialis posterioris Magnus, oder Dermo-costalis Owen.

"Subcutaneus abdominalis Widemann.

Daneben fand ich noch 2 ebenfalls bei allen von mir untersuchten Natatores vorkommende Hautmuskeln, von denen ich den einen mit

den andern mit Dermo-furcularis, bezeichnen will. 
Ich lasse nun die Beschreibung der einzelnen Muskeln folgen und beginne mit dem

\section{Constrictor colli Owen.}

Derselbe besteht wie beim Aptery $x$ aus 2 über einander liegenden Schichten, von denen jedoch nur diejenige, die Wiedemann mit Subcutaneus colli bezeichnet, eine bedeutende Entwicklung aufweist. Sie wird deshalb auch zuerst von mir beschrieben.

Die Fasern des Subcutaneus colli entspringen hauptsächlich von dem unteren Theil der Querleiste des Hinterhauptes. Nur eine kleine Partie Fasern kommt von dem Fortsatz, der ,theils dem Zitzenfortsatz, theils auch dem Griffelfortsatz des Schläfenbeins des Menschen und mehrerer Säugethiere analog ist". Von ihrer Ursprungsstelle nimmt auf jeder Seite des Halses die Muskellage in ihrem Verlaufe nach hinten so lange an Breite $\mathrm{zu}$, bis die obersten Fasern, d. h. diejenigen, die der Mittellinie des Hinterhalses am nächsten liegen, diese letztere, die untersten dagegen die gleiche Linie des Vorderhalses erreicht haben. Der erste Fall tritt in Folge der weit hinten am Schädel liegenden Ursprungsstelle der Fasern an einer höheren Stelle ein als der zweite. Die obersten Fasern erreichen nämlich die in Frage kommende Linie der Rückenflur schon oberhalb des unteren Endes des obersten Drittels des Halses, während die untersten Fasern an die Unterflurmittellinie erst am obersten Theil des zweiten Halsdrittels gelangen. Sind beide Fälle eingetreten, dann laufen an jeder Halsseite sowohl auf der Rücken- als auch auf der Unterflur die Fasern, nur durch einen schmalen Spalt von einander getrennt, bis zur Theilstelle der in Betracht kommenden Fluren, also ungefähr bis zum Ende des zweiten Drittels des Halses nach hinten. Von dieser Stelle aus aber convergiren die Fasern dieser Schicht auf jeder Halsseite etwas und zwar die bisher am Hinterhals verlaufenden in stärkerem Masse als die übrigen, und wenden sich, anfangs die ganze Unterflurhälfte, dann aber nur den inneren Theil derselben überstreichend der Furcula zu, an deren untere Hälfte sie sich inseriren. Diese Muskelschicht ist, ausgenommen eine kurze Strecke an ihrer Ursprungs- und Insertionsstelle, auf ihrem ganzen Verlauf mit der sie bedeckenden Haut resp. der sie überlagernden zweiten Schicht des C o n s tri c t or colli fest durch Bindegewebe verbunden.

Die zweite Schicht des in Rede stehenden Muskels, die direct unter der Haut liegt, ist, wie schon erwähnt, nicht sehr mächtig: entwickelt. Sie bildet keine Scheide, die den ganzen Hals umgiebt, sondern ist nur auf der vorderen Seite desselben kräftiger ausgebildet und erstreckt sich. von der Kehle bis zur Mitte des Halses, bei Mergus vielleicht noch eine kleine Strecke weiter nach hinten. Ihre Fasern verlaufen bei allen von mir untersuchten Schwimmvögeln, mit Ausnahme von Mergus, in einiger Entfernung von der Mittellinie der Rückenflur beginnend, unter immer gleichem 
Winkel schief nach hinten und unten stossen auf der Mittellinie der Unterflur, eine Naht bildend, zusammen. Bei Mergus fangen die Fasern nicht in einiger Entfernung sondern schon nahe der Mittellinie der in Frage kommenden Flur an, verhalten sich aber im Uebrigen wie eben geschildert wurde. In Folge des schiefen Verlaufs der Fasern liegt das Verbreitungsgebiet dieser Schicht am Hinterhals etwas höher als am Vorderhals. Die Fasern sind mit der sie bedeckenden Haut durch Bindegewebe verbunden.

Der Constrictor colli breitet sich also nur unter der Haut des Halses aus, und zwar an der vorderen Hälfte unter der ganzen Haut, an der hinteren Hälfte zum grössten Theil unter der Haut des Vorderhalses. Er wird demnach den grössten Theil der am Hals befindlichen Haut falten und dadurch die in ihr sitzenden Federn sträuben. Daneben wird auch der Subcutaneus colli den Kopf heben, oder wenn derselbe fixirt ist, einen Druck auf die sehr erweiterte Speiseröhre, namentlich auf den unteren Theil derselben ausüben und auf diese Weise beim Entleeren derselben mit thätig sein.

Triangularis juguli Wiedemann. Kehlhautmuskel. Dieser Muskel entspringt bei den von mir untersuchten Schwimmvögeln nicht immer in gleicher Weise. Bei Harelda glacialis und Anas clangula nimmt er seinen Ursprung nur von einer, bei Anas domestica, Anser domesticus und Mergus merganser dagegen von 2 verschiedenen Stellen der Unterkieferhälfte. Bei den zuerst genannten Gliedern dieser Ordnung liegt die Ursprungsstelle des ganzen Muskels und bei den an zweiter Stelle aufgezählten Schwimmvögeln die Ursprungsstelle des Haupttheils dieses Muskels an der Innenfläche des betreffenden Skelettstiickes und erstreckt sich ïber den hinteren Theil des Os dentale und den vorderen Theil des $\mathrm{Os}$ angulare, also ungefähr über denjenigen Theil der Unterkieferhälfte, der die grösste Höhe erreicht. Der kleinere Theil des in Rede stehenden Muskels entspringt stets in Form eines Bandes von der unteren Kante des hinter der Gelenkfläche auftretenden Fortsatzes des Unterkiefers. Die Fasern des Theils, der bei Harelda und Anas clangula den ganzen Muskel, bei den übrigen oben namhaft gemachten Schwimmvögeln den Haupttheil desselben repräsentirt, verbinden sich gleich hinter ihrer Ursprungsstelle mit der sie bedeckenden Haut durch Bindegewebe, laufen in fast wagrechter Richtung der Mittellinie des Kinns zu und bilden entweder dort eine Naht oder inseriren sich an eine Sehne. Das Erstere ist der Fall bei Harelda und Anas clangula, das Letztere bei Anas domestica, Anser domesticus und Mergus merganser. Diese Sehne entspringt von der Spitze des Unterkieferwinkels und erstreckt sich, der Haut dicht anliegend, so weit nach hinten als die Fasern des in Rede stehenden Muskels reichen. In ihrem Verlaufe nach hinten bleibt sie aber nicht gleich breit, sondern wird bei Mergus schmäler, während sie bei Anas 
und Anser anfangs etwas an Breite zunimmt, dann aber an der Stelle, an welcher die von verschiedenen Ursprung'sstellen kommenden Fasern sich berïhren, eine ellipsenähnliche Verbreiterung erfährt, um in ihrem weitern Verlauf nach hinten allmählig zu verschwinden.

Der hintere Theil des Triangularis ist, wie schon bemerkt, bandförmig, läuft in schräger Richtung der Sehne zu und geht erst in der Nähe derselben eine innige Verbindung mit der Haut ein. Geschieht dies, so breiten sich auch seine Fasern, die bis dahin einen Muskel von immer gleicher Breite bildeten, in einer grösseren Fläche unter der Haut aus.

Der Tri a n gularis kommt bei Anas domestica, Anser domesticus und Mergus merganser unter die Haut zu liegen, die sich zwischen den beiden Unterkieferhälften ausspannt, bei Harelda und Anas clangula dagegen erstreckt er sich nicht ganz so weit nach hinten. Contrahirt er sich, so faltet er die ihn bedeckende Haut und sträubt auf diese Weise die Federn derselben. Zugleich wird er wohl auch, namentlich der hintere Theil, beim Verschlucken der Nahrung eine gewisse Rolle mitspielen.

\section{Der Dermo-transversalis Owen}

ist ein Muskel, der nicht allen Schwimmvögeln zuzukommen scheint, ich fand ihn nur bei Colymbus glacialis. Bei ihm entsprang: er auf jeder Körperseite von dem untern schrägen Fortsatz des 8. Halswirbels (von oben an gezählt), lief in Gestalt eines schmalen Bandes nach hinten und inserirte sich an die Aussenseite desjenigen Theils der Rückenflur, der den Unterhals bedeckt. Er zieht, falls er sich contrahirt, den eben näher bezeichneten Theil der Halshaut nach vorne und spannt vielleicht auch den Theil, welcher dem Vorderrïcken aufliegt.

Subcutaneus thoracicus Wiedemann. Brusthautmuskel.

Dieser bandförmige Muskel kommt in allen Fällen von dem obern äussern Theil der Sehne, mittelst deren der $\mathrm{M}$ u s c u l u s p e c t o ralis major sich an die Leiste des Humerus-Kopfes inserirt. Von seiner Ursprungsstelle aus läuft er neben dem hintern Rand der Unterflur nach hinten; da aber bei den von mir untersuchten Schwimmvögeln, mit Ausnahme der Schellente, der Theil der Unterflur, welcher der Brust aufliegt, dieselbe (d. h. die Brust) ganz bedeckt, so läuft der in Rede stehende Muskel auch zugleich parallel dem hintern Rande des grossen Brustmuskels. In allen Fällen inserirt er sich an den untern äussern Theil des Unterflurastes. Bei Anas clangula ist der Brusttheil der Unterflur nicht so mächtig entwickelt und der Muskel geht, da er dicht neben der hintern Grenze der Flur zu liegen kommt, nicht parallel dem hintern Rand des Musculus pectoralis major, sondern

Cab. Journ. f. Ornith. XXXII. Jahrg. No. 167 u. 168. Juli u. October 1884. 
uiber ihn selbst nach hinten und unten. Stets ist der Muskel mit der ihn bedeckenden Haut und, soweit er neben der Unterflur verläuft, auch mit dieser fest durch Bindegewebe verbunden. $\mathrm{Er}$ wird daher im Fall er sich zusammenzieht die Brusthaut falten und die Federn des dort befindlichen Theils der Unterflur sträuben.

\section{Dermo-spinalis 0 wen.}

Den eben angeführten Namen habe ich für den jetzt zu beschreibenden Muskel gewählt, weil derselbe seiner Lage und seinem Verbreitungsgebiet nach dem Muskel entspricht, welchen Owen bei der Schilderung der Hautmuskeln des Apteryx so bezeichnet hat. Allerdings entspringen seine Fasern nicht wie bei dem eben genannten Vogel von den obern Fortsätzen der 3 vordern Rückenwirbel, sondern bei allen von mir untersuchten Schwimmvögeln von der Mitte desjenigen Theils des Rückgratrains, der dem Vorderrücken und dem Hinterhals aufliegt. Von ihrer Ursprungsstelle aus laufen dieselben auf jeder Körperseite in einem flachen Bogen (dessen convexe Seite nach vorne gekehrt ist) unter der Rückenflurhälfte und dem Rumpfseitenrain hin und endigen, zum Theil von den Fasern des Subcutaneus colli überdeckt, an dem äussern, d. h. dem Rücken zu gelegenen Theil der Unterflur. Dieser Muskel ist auf seinem ganzen Verlauf fest mit der ihn bedeckenden Haut verbunden und desshalb im Stande, dieselbe zu falten und dadurch die in ihr steckenden Federn zu sträuben. Vielleicht übt er auch dadurch, dass er den Theil der Unterflur, an welchen er sich inserirt, nach dem Rücken zu zieht, einen, allerding:s unbedeutenden, Druck auf den untern Theil der Speiseröhre aus.

\section{Dermo-iliacus 0 wen.}

Nach meinen Untersuchungen nimmt dieser Muskel seinen Ursprung nicht immer von derselben Stelle. Bei Anas clangula kommt er von dem obern der Wirbelsäule anliegenden Theil des Os ilium, bei Harelda hingegen entspringt er von dem obern Fortsatz des vorletzten, bei Mergus von der gleichen Stelle des drittletzten und endlich bei Colymbus von dem obern Fortsatz des letzten Brustwirbels. In allen Fällen aber fängt er mit einer kurzen Sehne an und läuft, fast geradlinig und immer gleich breit bleibend, der Schulterflur zu. In seinem Verlaufe, auf dem er fest an die ihm aufliegende Haut gebunden ist, überstreicht er eine Strecke lang die Rückenflur und dann den Rumpfseitenrain. An die Schulterflur inserirt er sich unmittelbar über den Fasern des Tensor cutis brachialis posterioris. An erster Stelle wird dieser Muskel die Haut, unter der er verläuft, falten und dadurch die in ihr steckenden Federn sträuben; sodann aber wird er vielleicht auch die Federn der Schulterflur in Folge ihrcr (d. h. der Federn) schon namhaft gemachten Stellung in geringem Masse sträuben und endlich, da die eben erst genannte Flur bis an den hintern 
Rand der Flughaut reicht, auch zum Spannen der letzteren etwas beitragen.

Tensor cutis brachialis posterioris Magnus, Dermocostalis Owen. Spanner der hintern Flughaut.

Er repräsentirt einen bandförmigen Muskel, der sowohl in Bezug auf die Anzahl der Köpfe, mittelst deren er entspringt, als auch was die Ursprungsstellen derselben anbetrifft, bei den von mir untersuchten Gliedern nicht immer das gleiche Verhalten zeigt. Bei Colymbus und Harelda nimmt er seinen Ursprung mit 3 Köpfen von der 3. 4. und 5., bei Mergus, Anas clangula und Cereopsis nur mit 2 Köpfen von der 4. und 5. untersten Rippe. Bei dem zuerst genannten Vogel, dem Colymbus, gehen die Köpfe unmittelbar unter der Abgangisstelle des Proc. unc. von den Rippen ab und zwar der Haupttheil, mehr als die Hälfte der Fasern umfassend, von der vordern Kante der 4, die übrigen zu gleichen Theilen von denselben Stellen der beiden andern schon näher bezeichneten Rippen. Bei den übrigen von mir untersuchten Natatores entspringen die Köpfe ungefähr von der Mitte der Strecke, die zwischen der Abgangsstelle der Proc. unc. und der Ansatzstelle der Sternocostalknochen liegt. Der Haupttheil der Fasern kommt bei Harelda in 2 gleichen Portionen direct von der vordern Kante der 4. und 5. Rippe, der ïbrige Theil mittelst einer kurzen Sehne von derselben Stelle der 3. Rippe. Von den andern oben aufgezählten Schwimmvögeln nimmt bei Cereopsis der Haupttheil, bei Mergus die Hälfte der Fasern von der schon mehrmals bezeichneten Stelle der 4. ihren Ursprung, bei Anas clangula dagegen von der 5. untersten Rippe, während die übrigen Fasern bei den beiden ersten direct von der äusseren Fläche der 5., bei der letzteren mittelst einer langen Sehne von der vordern Kante der 4. Rippe abgehen. In allen Fällen aber vereinigen sich die getrennt entspringenden Köpfe erst in einiger Entfernung von ihrer Ursprungsstelle zu einem, wie schon beiläufig bemerkt, bandartigen Muskel. Derselbe läuft dem Rand der hintern Flughaut entlang: bis zur Schulterflur, an dem untern Ende derselben endigt der grösste Theil seiner Fasern, während ein kleiner Theil weiter am Rande desjenigen Theils der hintern Flughaut verläuft, der ausserhalb der Schulterflur liegt, aber nach seiner Trennung von dem Haupttheile sofort sehnig wird. Die Fasern sind, soweit sie am Rande der Flughaut verlaufen, ziemlich fest mit derselben verbunden.

Der Muskel wird bis zu einem gewissen Grade die ansgespannte hintere Flughaut falten und, wenn dieses Mass überschritten wird, höchst wahrscheinlich auch die Federn der Schulterflur in Folge ihrer Stellung sträuben. Beim Entfalten des Flügels wird er die hintere Flughaut spannen und vielleicht auch beim Zusammenlegen desselben eine Rolle mit spielen, 'd. h. auf den Flügel selbst einwirken. 


\section{Der Subcutaneus abdominalis Wiedemann.}

Ba ch ha tmuskel

ist unter allen bei den Natatores vorkommenden Hautmuskeln am mächtigsten entwickelt. Er repräsentirt ein breites Muskelband, das direct mittelst seiner Fasern von der vorderen Kante des mittlern Theils des $\mathrm{Os} p \mathrm{ubis}$ entspringt und unter den äussern Federreihen der Unterflur schief nach vorne verläuft, um sich an den unteren Theil der innern Kante des Astes der eben genannten Flur anzusetzen. Auf seinem Verlaufe ist dieser Muskel fest an die ihn bedeckende Haut durch Bindegewebe gebunden und nimmt, nach vorne verlaufend, an Breite in der Weise zu, dass er an seiner Insertionsstelle ungefähr $1 / 3$ mal breiter ist als an seiner Ursprungsstelle.

Er sträubt nicht nur die Federn des Unterflurastes und die des anliegenden Theils der Unterflur selbst, sondern, in Folge seiner innigen Verbindung mit der Haut, auch die Federn des dem A b d omen aufliegenden Theils der Unterflur.

Bei allen von mir untersuchten Schwimmvögeln fand ich eine, allerdings in nur geringer Entwicklung auftretende Muskellage, die sich zwischen den beiden Nebenflügeln, den Parapterum und Hypopterum, ausspannt und welche ich als

\section{Musculus pteronaeus}

bezeichnen will. Die Fasern dieser Muskellage divergiren, da das Hypopterum in der Regel etwas länger ist als das Parapterum, auf ihrem Verlaufe unter den der Schulterflur anliegenden Theil der hinteren Flughaut, sind aber stets mit der sie bedeckenden Haut fest verbunden und somit befähigt, die Federn der beiden Nebenflügel, welche unter einem sehr spitzen Winkel in der Haut stecken und in der Regel dachförmig übereinander liegen, von einander $\mathrm{zu}$ entfernen.

\section{Der Dermo-furcularis}

entspringt, wie schon sein Name andeuten soll, von der Furcula und zwar oberhalb der Insertionsstelle des Subcutaneus colli an diesem Knochen in Form eines Bandes, läuft dann auf jeder Körperseite der F u r c u la entlang nach hinten und wendet sich der Rückenflur zu. Seine Fasern divergiren während des Verlaufes etwas und inseriren sich an den auf der Grenze zwischen Hals und Brust liegenden Theil des Rückgratrains, sind aber schon vorher, soweit sie unter die Rückenflur zu liegen kommen, fest mit der sie bedeckenden Haut verbunden. Dieser Muskel wird namentlich die Haut des Vorderrückens und des Hinterhalses spannen.

Was nun die Zahl der Muskeln anbetrifft, die an die Conturfedern sich inseriren, so betrug dieselbe bei allen von mir untersuchten Schwimmvögeln ziemlich regelmässig 4 und nur an ein- 
zelnen Stellen, die bei den einzelnen Gliedern im Bezug auf ihre Lage etwas verschieden sind, stieg ihre Zahl auf 6. Bei Harelda fand ich diese Zahl ziemlich regelmässig an den Federn, welche den hintern Theil der Rückenflur bilden; bei Anas clangula und Mergus merganser dagegen tritt diese Zahl ebenfalls ziemlich regelmässig an den Federn der Schulterflur auf und bei Mergus ausserdem am Unterhals, sowohl an den Federn der Rücken- als auch der Unterflur. Die uibrigen oben aufgezählten Schwimmvögel habe ich nicht näher nach dieser Richtung hin untersucht, so dass ich nicht angeben kann, ob bei ihnen die Anzahl der Muskeln Verschiedenheiten darbietet.

\section{Grallatores, Sumpfögel.}

Untersucht wurden Crex pratensis, Scolopax gallinago und Tringa minuta (?)

Folgende Muskeln habe ich bei ihnen gefunden:

Den Constrictor colli Owen

"Triangularis juguli Wiedemann.

” Dermo-transversalis Owen.

"Dermo-furcularis.

"Subcutaneus thoracicus Wiedemann.

"Dermo-spinalis Owen.

"Dermo-iliacus Owen.

"Tensor cutis brachialis posterioris Magnus oder Dermo-costalis Owen.

Subcutaneus a bdominalis Wiedemann.

Neben den eben aufgezählten Hautmuskeln fand ich bei den von mir untersuchten Grallatores noch 2 andere Muskeln, welche ebenfalls zur Bewegung der Haut dienen und von denen ich den einen mit

den andern mit

Musculus furculo-cephalicus,

bezeichnen will.

Musculus humero-spinalis

Ehe ich zur speciellen Schilderung der Hautmuskeln übergehe, halte ich es für nöthig, einige Bemerkungen vorauszuschicken. Das Material zu meinen Untersuchungen wurde grösstentheils in den Monaten August, September und October gesammelt und soweit es nicht gleich frisch untersucht werden konnte, in ungefähr $70 \%$ Alkohol aufbewahrt. Obwohl im allgemeinen die so conservirten Vögel für spätere Untersuchungen der Hautmuskulatur vollkommen tauglich waren, machten doch, aus den oben schon angeführten Gründen, die Sumpfvögel davon eine Ausnahme. Ich bin daher leider nicht im Stande, über die eben aufgezählten Muskeln immer genügend Aufschluss zu geben. Ich werde aber, sobald es in meinen Kräften steht, die Liucken auszufüllen suchen und behalte mir auch vor, etwaige Irrthümer, die in der jetzt folgenden Schilderung der Hautmuskeln aus den schon ange- 
gebenen Gründen vielleicht untergelaufen sind, später zu berichtigen.

Nach diesen Bemerkungen gehe ich zu den Hautmuskeln selbst über und beginne mit

\section{Constrictor colli Owen.}

Beide Muskellagen sind gleich mächtig entwickelt. Die Fasern des Subcutaneus colli entspringen sowohl bei Crex als auch bei Scolopax und Tringa über der äusseren Ohröffnung vom Rande der Orbitalhöhle, laufen auf jeder Seite des Halses bogenförmig nach hinten und endigen zum Theil an der Rückenflur und zum Theil an der Unter- und Schulterflur. In diesem Verlaufe, aut dem die Lage anfangs an Breite zunimmt, beschreiben die vordersten Fasern einen viel flacheren Bogen als die hintersten. Diesem Umstande und der weit nach hinten am Schädel liegenden Ursprungsstelle ist es zuzuschreiben, dass der grösste Theil der Fasern an der vordern Halshälfte unter die Rückenflur, sie mehr oder minder vollständig iuberstreichend, zu liegen kommt. Am vollständigsten ist dies der Fall bei Tringa, bei dem nur ein schmaler Streif zu beiden Seiten der Mittellinie dieser Flur frei bleibt, während bei Scolopax und Crex der Raum ziemlich bedeutend ist. Auf der hinteren Hälfte des Halses ist es der grösste Theil der Unterflur, der in Folge des bogenförmigen Verlaufs der Fasern überstrichen wird. Allerdings sind es nicht sämmtliche Fasern, die an diesem Halstheil unter die Unterflur zu liegen kommen, da ein Theil, der bei Tringa und Crex nur wenig, bei Scolopax dagegen eine bedeutende Anzahl der Fasern dieser Muskellage umfasst, an der Rückenflur endigt. Dieser Muskeltheil bildet nach seiner Differenzirung von der Gesammtfasermasse einen schmalen, bandförmigen Muskel, der auf jeder Körperseite an der Aussenseite der Rückenflur innig durch Bindegewebe mit derselben befestigt, nach hinten verläuft und am Hinterhals an derselben endigt. Der Theil der Fasern hingegen, der sich der Unterflur zuwendet, erreicht mit den vordersten Fasern die Aussenseite derselben in der Mitte des Halses an ihrer Theilstelle und bildet dann ebenfalls einen flachen bandförmigen Muskel, welcher den äusseren Theil der iu Frage kommenden Flur überdeckend nach hinten verläuft und zum grössten Theil auf der Grenze zwischen Hals und Brust an ihr endigt. Ein kleiner Theil der Fasern wendet sich der Schulterflur zu und endigt am obern Theil derselben, mit Ausnahme einiger Fasern, die sehnig werden und sich mit dem Spanner der vorderen Flughaut vereinigen. Der Subcutanus colli ist, abgesehen von einer kleinen Strecke hinter seiner Ursprungsstelle, auf seinem ganzen Verlauf fest mit der ihn bedeckenden Haut und der ihn iiberlagernden 2 ten Schicht des Constri c tor c olli durch Bindegewebe verbunden. Die 2 te Schicht des in Rede stehenden Muskels ist bei den von mir untersuchten Grallatores nicht immer in gleicher Weise ausgebildet. Bei Tringa und Scolopax breitet sie sich nur 
unter der Haut der vordern Halshälfte, bei Crex hingegen unter der ganzen Halshaut aus, doch ist auch bei letzterem die hintere Hälfte nicht so kräftig als die vordere entwickelt. Stets aber war diese Schicht mächtiger als bei den von mir untersuchten Natatores und bildete auf der vordern Halshälfte eine zusammenhängende Scheide, die allerdings auf dem Vorderhals stärker als auf der entgegengesetzten Seite ausgebildet war, und deren Fasern auf jeder Seite des Halses von hinten nach vorne und unten verliefen und auf der Mittellinie der ungetheilten Unterflur eine Naht bildeten. Bei Crex, bei dem, wie schon erwähnt, diese Schicht auch unter der Haut der hintern Halshälfte auftritt, verliefen die Fasern in gleicher Richtung zwischen der Rïickenflur und der Aussenseite der Unterflurhälfte. Die Fasern dieser Schicht sind fest mit der sie bedeckenden Haut und, soweit sie uiber die Fasern des Subcutaneus colli zu liegen kommen, auch mit denselben durch Bindegewebe verbunden. Bei den Grallatores verrichtet der Constrictor colli in Folge seines andern Verbreitung'sgebietes auch eine etwas andere Function als bei den Natatores. Zwar wird er auch, da er sich an den am Halse verlaufenden Theil der Rücken- und Unterflur inserirt, die Haut des Halses falten und dadurch die Federn desselben sträuben, doch spannt er auch daneben den Theil der Unterflur, der die Brust bedeckt, und unterstützt dadurch, wenn gleichzeitig der Subcutaneus abdominalis sich contrahirt, was ja beim Sträuben und Schütteln des Gefieders wahrscheinlich immer der Fall sein wird, den letzteren. Dasselbe ist höchst wahrscheinlich auch auch der Fall bei dem Theile, der an der Rückenflur endigt. Contrahirt sich gleichzeitig mit ihm der Theil des Dermoiliacus, der neben der Aussenseite der Rückenflur nach vorne verläuft, so wird die Haut, die dem Rücken aufliegt, gespannt und die dort befindlichen Federn, in Folge der schon mehrfach erwähnten Stellung, meiner Meinung nach, gesträubt. Die gleiche Function wird endlich auch der Theil, der dem oberen Ende der Schulterflur zuläuft, übernehmen; auch er wird den Spanner der hinteren Flughaut vielleicht in gewissem Sinne unterstützen.

Ueber den Triangularis juguli Wiedemann.

" "Dermo-transversalis Owen und

" Dermo-spinalis Owen

kann ich aus" den schon angeführten Gründen nur wenig sagen. Der erstere entspringt stets mit 2 Köpfen von der Unterkieferhälfte, von denen der vordere stets die Hauptmasse der Fasern umfasst.

Der Dermo-transversalis ist schmal, bandförmig und inserirt sich an die Aussenseite des Theils der Rückenflur, welcher den Unterhals bedeckt.

Der Dermo-spinalis ist relativ nicht so mächtig entwickelt bei Crex und Scolopax als bei den Natatores, während bei Tringa er hingegen noch kräftiger ausgebildet zu sein scheint. 


\section{Dermo-furcularis.}

Dieser Muskel ist relativ mächtiger als bei den Schwimmvögeln entwickelt und entspringt vom oberen Ende der F u r c ula und zwar, da seine Fasern sich gleich an der Ursprungsstelle zu einer Anzahl isolirt liegender Muskelbündel gruppiren, an einer ziemlich bedeutenden Strecke dieses Knochens. Von ihrer Ursprungsstelle aus laufen die Bïndel stark divergirend unter dem Rumpfseitenrain der Rüickenflur zu und inseriren sich bei Crex und Scolopax an denjenigen Theil derselben, der dem Vorderrücken und Hinterhals aufliegt. Bei Tringa, bei der dieser Muskel am mächtigsten entwickelt ist, heftet er sich, den Theil des Subcutaneus colli, der an der Rückenflur endigt, überdeckend, an die Aussenseite des Theils, welcher die hintere Hälfte des Halses und ebenfalls den Vorderrïcken bedeckt. Auf ihrem Verlauf unter der Haut sind die Fasern nur lose an dieselbe befestigt. Dieser Muskel wird sowohl die Haut des Rückens als auch des Halses anspannen und vielleicht auch den Theil der Haut, an die er sich inserirt, falten und die in ihr sitzenden Federn sträuben.

Subcutaneus thoracicus Wiedemann. Brusthautmuskel.

Es ist dies ein Muskel, der bei allen von mir untersuchten Sumpfrögeln nicht wie bei den Natatores von, sondern neben der Sehne des grossen Brustmuskels von der obern Leiste des $\mathrm{Hu}$ mer u s entspringt, eine kurze Strecke neben dem hintern Rande des eben genannten Muskels hin, dann aber über ihn selbst geradlinig: nach hinten und unten läuft und sich, nachdem er kurz vorher etwas an Breite zugenommen hat, mit dem grössten Theil seiner Fasern an die Aussenseite, mit einem kleinen Theil an die Unterseite des Astes der Unterflur inserirt. Er behält auf seinem Verlaufe, mit Ausnahme der schon namhaft gemachten Stelle, immer gleiche Breite und ist, soweit er über den grossen Brustmuskel verläuft, fest mit der ihn bedeckenden Haut verbunden. $\mathrm{Er}$ übt dieselbe Function wie bei den Schwimmvögeln aus, indem er die ihn bedeckende Haut faltet und die in ihr sitzenden Federn dadurch zum Sträuben bringt.

\section{Der Dermo-iliacus 0 wen}

zeigt bei der in Rede stehenden Gruppe eine stärkere Ausbildung: als bei den Natatores. Seine Fasern entspringen mittelst einer Sehne vom vordern Rand des $\mathrm{Os}$ ilium und laufen nur eine kurze Strecke neben der Aussenseite der Rückenflur in Gestalt eines bandförmigen Muskels nach vorne, worauf dann eine Differenzirung der Fasern in 2 gleiche aber nach verschiedenen Richtungen verlaufende Partien eintritt. Der eine Theil behält die Richtung, die anfangs der ganze Muskel einschlug, bei und läuft in einiger Entfernung neben der Aussenseite der Rückenflur 
nach vorne bis zur Theilstelle derselben, also ungefähr bis zum Vorderrïcken. An dieser Stelle breiten sich die Fasern fächerförmig aus und inseriren sich zur Hälfte an die Aussenseite der Rïckenflur, zur anderen Hälfte an den anliegenden Theil des Rumpfseitenrains. Die andere Partie läuft von ihrer Differenzirungsstelle aus bogenförmig der Schulterflur zu und inserirt sich mit dem Spanner der hinteren Flughaut gemeinschaftlich an das untere Ende derselben. Beide Partien sind in ihrem Verlaufe fest mit der sie bedeckenden Haut verbunden, und der Theil, der neben der Rückenflur verläuft, steht ausserdem auch fest mit der Aussenseite dieser Flur durch Bindegewebe in Zusammenhang. Die letztere Partie wird, wenn sie sich auf beiden Körperseiten zugleich contrahirt, die Haut, die sie bedeckt, falten und auf diese Weise die Federn des dort befindlichen Theils der Rïckenflur sträuben, zugleich aber auch die Haut, welche dem Hinterhals aufliegt, spannen und so ebenfalls mit zum Sträuben der Federn beitragen. Der andere Theil verrichtet dieselbe Function wie bei den Schwimmvögeln.

Tensor eutis brachialis posterioris Magnus, Dermocostalis 0 wen. Spanner der hinteren Flughaut.

Aus den schon angeführten Gründen konnte ich diesen Muskel nur bei Crex näher studiren. Bei diesem Vogel entspringt er in geringer Entfernung von der Abgangsstelle des Processus uncinatus der 3. und 4. untersten Rippe und zwar mit dem Haupttheil seiner Fasern von der Aussenfläche der ersteren, mit dem kleineren Theil von der vorderen Kante der letzteren. Beide Theile vereinigen sich kurz nach ihrer Ursprungstelle zu einem bandförmigen Muskel, der in seinem Verlauf nach oben gleich breit bleibt und sich mit dem grössten Theil seiner Fasern an das untere Ende der Schulterflur inserirt, während ein kleiner Theil der Fasern, die aber nach ihrer Abzweigung sofort sehnig: werden, an den übrigen ausserhalb der Schulterflur liegenden Theil der hinteren Flughaut laufen. Was seine Function und sein übriges Verhalten anbetrifft, so stimmt er ganz mit dem der Natatores überein.

Subcutaneus abdominalis Wiedemann. Bauchbaut muskel.

Derselbe entspringt bei allen von mir untersuchten Gliedern dieser Ordnung mit einer kurzen Sehne von der vorderen Kante des unteren Theils des $\mathrm{Os}$ pubis. Er repräsentirt nicht wie bei den Natatores einen bandförmigen Muskel, der unter dem äusseren Theil der Unterflurhälfte verläuft und sich mit seiner ganzen Fasermasse an den Ast der Unterflur inserirt, sondern er besteht aus einer Anzahl Muskelbündel, die zwar ebenfalls nach vorne verlaufen, von welchen aber der grösste Theil sich an die Aussen- 
seite der Unterflurpartie, die das A b d o m e n und den hinteren Theil der Brust bedeckt, inseriren und nur ein kleiner Theil dem Ast der Unterflur sich zuwendet. An die ihn bedeckende Haut ist dieser Muskel nur sehr lose befestigt. Er übt, trotz seines andern Verhaltens, im Grossen und Ganzen dieselbe Wirkung wie bei den Schwimmvögeln aus.

Bei den von mir untersuchten Sumpfvögeln, sowie bei den Mitgliedern einiger anderen Vogelordnungen fand ich einen Muskel, der mit wenigen Ausnahmen von der Furcula entspringt, nach vorne verläuft, dabei eine mehr oder weniger innige Verbindung mit der Haut eingeht, also als Hautmuskel fungirt, und dann bei den einzelnen Ordnungen an verschiedene Stellen des Kopfes sich inserirt. Da kein Anatom, mit Ausnahme von D'Alton, diesen Muskel erwähnt und der eben angeführte Forscher ihn bei der Schilderung der Hautmuskeln der Eulen mit einem falschen von Wiedemann für einen ganz anderen Muskel gegebenen Namen bezeichnet, demnach ein eigentlicher Name für ihn nicht existirt, so sehe ich mich genöthigt, ihn selbst zu benamsen. Ich werde ihn als M. Furculo-cephalicus

bei der Schilderung der Hautmuskeln der einzelnen Gruppen anführen.

Der M. Furculo-cephalicus

kommt sowohl bei Grex und Tringa als auch bei Scolopax als bandförmiger Muskel von dem Ligamentum sterno-furculare und läuft in der eben erwähnten Form an der Innenfläche der Furcula entlang bis er die Unterflurbälfte erreicht hat. Von dieser Stelle an wird er etwas breiter und geht bis zur Theilstelle der Unterflur, also ungefähr bis zur Mitte des Halses, neben den Fasern des Subcutaneus colli auf den inneren Theil der Unterflurhälften verlaufend, eine innige Verbindung mit der Haut ein. Von dieser Stelle aus aber löst der Muskel auf jeder Seite seine Verbindung wieder, nimmt seine schmale ursprüngliche Form wieder an und läuft nach vorne, um sich an den Körper des Zungenbeins zu inseriren. Er unterstützt den Constrictor colli, indem er die Haut, an welche er befestigt ist, faltet und so die Federn sträubt, andererseits wird er auch die Zunge nach hinten ziehen und so die Mundhöhle vergrössern.

Auf eine weitere Muskellage, welche ich mit

\section{Musculus humero-spinalis}

bezeichnen will und die, wie es mir schien, bei Crex und Scolopax sich zwischen den beiden einander zugekehrten Seiten der Rückenund Schulterflur, bei Tringa dagegen auch zwischen Rücken- und Oberschenkenflur ausspannte, kann ich leider aus den schon mehrfach angeführten Gründen nicht eingehen. Die Zahl der Muskeln, welche sich an die einzelnen Federn inseriren, beträgt nach meinen Untersuchungen sowohl bei Crex als auch bei Scolopax und Tringa immer 4. 


\section{Gallinaceis. Rasores, Hühnervögel.}

Untersucht wurden Gallus domesticus und zum Theil auch Nothura maculosa und Phasianus colchicus; gefunden wurden folgende Muskeln:

Der Constrictor colli Owen.

"Triangularis juguli Wiedemann.

" Dermo-transversalis Owen.

"Musculus frontalis Tiedemann.

" Dermo-furcularis.

"Subcutaneus thoracicus Wiedemann.

"Dermo-iliacus Owen.

"Tensor cutis brachialis posterioris Magnus, oder Dermo-costalis Owen.

"Subcutaneus abdominalis Wiedemann. und endlich noch ein Muskel, den ich mit bezeichnen will. Musculus gastro-lumbalis

Constrictor colli Owen.

Dieser Muskel zeigt, sowohl was seine Ausbildung als auch den Verlauf der Fasern der beiden Schichten anbetrifft, viel Aehnlichkeit mit dem Muskel gleichen Namens bei den Schwimmvögeln. Es ist auch hier der Subcutaneus colli, der am mächtigsten entwickelt ist, während die andere Lage wie bei den Natatores nur an dem Vorderhals der oberen Hälfte zu einiger Ausbildung kommt.

Die Fasern des Subcutaneus colli entspringen senkrecht über der äusseren Ohröffnung vom Schädel, verbreitern sich anfangs stark bis sie das Doppelte der ursprünglichen Breite erreicht haben, und laufen dann, fast immer dieselbe Form behaltend, bogenförmig (die convexe Seite dem Hinterhals zugekehrt) nach hinten und unten, um sich an den unteren Theil der Furcula $\mathrm{zu}$ inseriren. An der vorderen Hälfte des Halses kommen die Fasern dieser Muskellage zum grössten Theil unter die sehr entwickelte Rückenflur zu liegen, nur ein kleiner Theil tritt unter den Halsseitenrain, auf der anderen Halshälfte hingegen verlaufen die meisten Fasern unter der ebenfalls sehr mächtig ausgebildeten Unterflurbälfte und nur wenige unter den zwischen beiden eben genannten Hälften sich einschiebenden Unterrain. Die auf beiden Seiten des Halses verlaufenden Fasern berühren sich nicht auf der Rückenflur, sondern sind durch einen schmalen zu beiden Seiten der Mittellinie liegenden Raum, der nach hinten zu etwas breiter wird, getrennt. Auch auf der unteren Hälfte des Halses tritt keine Berührung der von beiden Seiten kommenden Fasern ein, obwohl der Zwischenraum, der beide von einander scheidet, in der Gegend des Kropfes bei einigen von mir untersuchten Hühnern kaum bemerklich war. Auch diese Schicht ist, mit Ausnahme einer kurzen Strecke an 
ihrer Ursprungs- und Insertionsstelle, fest mit der darüber befindlichen Haut und der sie überlagernden 2. Schicht des Constrictor colli durch Bindegewebe verbunden. Diese 2. Schicht des eben namhaft gemachten Muskels scheint nach meinen Untersuchungen nicht immer in derselben Ausbildung aufzutreten. Ich fand sie bei einigen von mir untersuchten Gliedern dieser Familie nur an der vorderen Hälfte des Halses, bei anderen hingegen am ganzen Halse ausgebildet. Den ersten Fall beobachtete ich bei mehreren Hühnern, während der letztere bei einem sog. spanischen Hahn recht ausgeprägt war. Auch die Ausbreitung der Fasern an den Seiten des Halses ist bei den Geschlechtern etwas verschieden. Bei den Hühnern fangen dieselben in einiger Entfernung von der Mittellinie der Rückenflur, bei den Hähnen hingegen an der eben genannten Linie selbst an. Sie laufen bei den letzteren dicht neben einander, bei den ersteren oft mehr oder minder isolirt nach vorne und unten. Soweit sie auf die ungetheilte Unterflur zu liegen kommen, bilden sie eine Naht, die mit der Mittellinie der eben erwähnten Flur zusammenfällt, kommen die Fasern aber auf ihrem Verlaufe an die Unterflurhälfte, so endigen sie an der Aussenseite derselben.

Die Richtung, welche die Fasern in ihrem Verlaufe an der Seite des Halses einschlagen, ist nicht immer dieselbe, indem die am oberen Theil des Halses verlaufenden eine mehr verticale, die am unteren Theil befindlichen eine mehr transversale Richtung einhalten. Ebenso wie bei den Natatores sind auch die Fasern dieser Schicht bei den Rasores fest an die sie bedeckende Haut befestigt.

Der Constrictor verrichtet bei der in Rede stehenden Gruppe genau dieselben Functionen wie bei der eben zum Vergleich herbeigezogenen Ordnung.

Triangularis juguli Wiedemann. Kehlhautmuskel.

In seinem ganzen Verhalten zeigt der eben angeführte Muskel viel Aehnlichkeit mit demjenigen von Mergus merganser, Anas domestica und Anser domesticus. Er entspringt wie bei den aufgezählten Schwimmvögeln zum grössten Theil von der inneren Seite des Os dentale und dem vorderen Theil des Os angulare, während der-kleinere Theil von dem oberen äusseren Ende des ebenfalls bei den Rasores hinter dem Gelenk auftretenden Fortsatzes kommt. Bei Gallus domesticus verhalten sich beide Theile dieses Muskels genau so wie bei den erwähnten Schwimmvögeln. Bei Phasianus ist solches auch mit dem vorderen Theil der Fall, während der hintere Theil ein etwas abweichendes Verhalten aufweist. Er ist kräftiger entwickelt als bei Gallus und geht gleich von seiner Ursprungsstelle an eine feste Verbindung mit der ihn bedeckenden Haut ein. Seine Fasern bilden auch keinen schmalen, bandförmigen Muskel, sondern verlaufen nach verschiedenen Richtungen. Diejenigen, welche unmittelbar neben 
den hintersten Fasern des Haupttheils an die Sehne sich heften, schlagen eine ziemlich wagrechte Richtung ein. Da sie aber, je weiter nach hinten sie sich an die Sehne inseriren, desto bogenförmiger verlaufen, so kommt es, dass die hintersten Fasern dieses Muskeltheils fast die entgegengesetzte Richtung als die vordersten einhalten.

Der Muskel übt dieselben Functionen wie bei den Schwimmvögeln aus.

\section{Dermo-transversalis 0 wen.}

Er ist sowohl bei Nothura als auch bei Gallus sehr mächtig entwickelt und setzt sich bei beiden aus einer Anzahl von einander getrennt verlaufender Muskelbänder zusammen, die mittelst kurzer Sehnen von den unteren Fortsätzen der mittleren Halswirbel entspringen. Bei Nothura beträgt nach meinen Untersuchungen die Zahl der Muskelbündel 8, bei Gallus dagegen nur 4; bei dem ersten Vogel entspringen dieselben in der schon angegebenen Weise von dem 4. bis 11., bei dem letzteren von dem 7. bis 11. obersten Halswirbel. Am kräftigsten entwickelt sind bei Nothura die mittelsten Partien, bei Gallus hingegen das oberste Band. In allen Fällen aber laufen diese Bänder von ihren Ursprungsstellen aus nach hinten. Sie inseriren sich, nachdem sie vorher etwas an Breite zugenommen haben, auf jeder Körperseite an die Aussenseite der Rückenflur und zwar bei Grallus am Unterhals, bei Nothura aber an den 2 untersten Dritteln des ganzen Hinterhalses. In ihrem Verlaufe unter der Haut sind diese Muskellagen nur sehr lose an dieselbe befestigt und behalten mit Ausnahme an der schon näher bezeichneten Stelle immer dieselbe Breite.

Der Dermo-transversalis übt einen Zug auf die Haut des Hinterhalses aus und spannt dieselbe.

Musculus frontalis Tiedemann. Stirnhautmuskel.

Dieser Muskel entspringt bei den von mir untersuchten Hühnern nicht von der Wurzel des Schnabels, sondern von dem am höchsten liegenden Theil des Augenhöhlenrandes. $\mathrm{Er}$ repräsentirt kein Muskelband, sondern besteht aus einer Reihe von Muskelbündeln, die, wie auch Tiedemann bei seiner Beschreibung des Stirnmuskels angiebt, mit Sehnenfasern vermischt sind, schief nach hinten verlaufen und sich an die Haut des Scheitels inseriren. Contrahiren sich dieselben, so werden sie die Haut von der Stirn bis zum Scheitel falten und die Federn derselben sträuben, ausserdem vielleicht die Haut, welche das Hinterhaupt bedeckt, spannen.

$$
\text { Der Dermo-furcularis }
$$

kommt wie bei den Grallatores vom oberen Ende der Furcula, differenzirt sich aber nicht wie bei der zum Vergleich herbeigezogenen Ordnung in eine Anzahl isolirt verlaufender Bündel, sondern seine Fasern wenden sich, eng neben einander liegend, der Rücken- 
flur zu und inseriren sich an den Theil derselben, welcher auf der Grenze zwischen Hals und Brust liegt. Soweit sie unter der Haut verlaufen, sind sie fest mit derselben durch Bindegewebe verbunden.

Dieser Muskel verrichtet dieselbe Function wie bei den Natatores.

Subcutaneus thoracicus Wiedemann. Brusthautmuskel.

Er repräsentirt einen Muskel, der wie der Dermo-trans versalis sowohl bei Gallus als auch bei Nothura mächtig entwickelt ist und bei beiden mit 2 Köpfen an zwei verschiedenen Stellen entspringt. Bei Nothura nimmt die Hälfte der Fasern mit einer langen bandförmigen Sehne von dem äusseren Ende der oberen Leiste des Humerus Kopfes ihren Ursprung, während die andere Hälfte ebenfalls mit einer gleich langen Sehne von dem oberen Ende der Scapula kommt. Bei den von mir untersuchten Exemplaren von Gallus domesticus entsprang dieser Muskel nicht von Skelettstücken, sondern von den Sehnen 2 er Muskel, die eine Hälfte von der Sehne des grossen Brustmuskeis, die andere hingegen von der Sehne, mittelst deren der Musculus suprascapularis sich an den unteren Höcker des Humerus ansetzt. Während bei Nothura die beiden von verschiedenen Stellen kommenden Partien sich nicht mit einander vereinigen, sondern getrennt neben einander der Unterflur zulaufen, tritt bei Gallus die Verschmelznng der Fasern sofort nach ihrer Ursprungsstelle ein. In beiden Fällen aber, mögen die Hälften getrennt oder vereinigt sein, nehmen sie in ihrem Verlaufe über den grossen Brustmuskel allmählich an Breite $\mathrm{zu}$, so dass, wenn sie die Unterflur erreicht haben, sie beinahe doppelt so breit als an ihrer Ursprungsstelle sind. Die Fasern dieses Muskels endigen an der unteren Hälfte der Aussenseite des Unterflurastes und sind in ihrem ganzen Verlauf fest durch Bindegewebe mit der sie bedeckenden Haut verbunden. der Natatores.

Dermo-iliacus 0 wen.

Dieser Muskel zeigt bei der in Rede stehenden Gruppe ein ähnliches Verhalten wie bei den Grallatores. Er entspringt mit einer kurzen Sehne von dem oberen Fortsatz des vorletzten oder in manchen Fällen von derselben Stelle des letzten Brustwirbels, läuft auf jeder Körperseite eine kurze Strecke unter der Rückenflur nach vorne und differenzirt sich dann wie bei den Grallatores in zwei nach verschiedenen Stellen der Haut verlaufende Partien, die aber an Fasermasse nicht gleich sind. Die eine Partie, den Haupttheil des gesammten Muskels ausmachend, behält die ursprüngliche Richtung bei und läuft, allmählich an Breite etwas 
zunehmend und fest mit der sie bedeckenden Haut verbunden, nach vorne bis zur Brustmitte. Dort divergiren die Fasern und endigen zur Hälfte an der Aussenseite der Rückenflur und zur Hälfte an den anliegenden Theil des Rumpfseitenrains. Der andere, an Faseranzahl geringere Theil, läuft nach seiner Differenzirung in einen flachen Bogen unter der Rückenflur und dem anliegenden Theil des Rumpfseitenrains dem unteren Theil der Schulterflur zu und inserirt sich, nach meinen Untersuchungen, manchmal direct mittelst seiner Fasern, manchmal auch mittelst einer kurzen Sehne neben den Fasern des Spanners der hinteren Flughaut an die der Rückenflur zugekehrte Seite.

Der Dermo-iliacus übt bei den Rasores genau dieselben Eunctionen wie bei den Grallatores aus.

Tensor cutis brachialis posterioris Magnus, Dermocostalis 0wen. Spanner derhinteren Flughaut.

Bei Nothura fand ich denselben sehr stark, bei Gallus dagegen sehr wenig entwickelt, ja bei einem von mir untersuchten Exemplar fehlte er ganz. Er entspringt bei Gallus eine kleine Strecke unter der Abgangsstelle des Processus uncinatus mit einer kurzen Sehne von der Aussenseite der 2. oder 3. untersten Rippe, bei Nothura ebenfalls mit einer kurzen Sehne von derselben Fläche der 2. untersten Rippe, aber unmittelbar neben der Abgangsstelle des betreffenden Fortsatzes. In beiden Fällen läuft er aber, immer gleiche Breite behaltend, nach vorne der Schulterflur zu und inserirt sich bei Nothura mit dem grössten Theil seiner Fasern an das untere Ende derselben, während ein kleiner Theil, welcher aber gleich nach seiner Trennung sehnig wird, mit dem ausserhalb der Schulterflur sich ausspannenden Theil der hinteren Flughaut sich verbindet. Bei Gallus geht der Muskel vor seiner Endigung an den eben angeführten Stellen in eine bald längere bald kürzere Sehne über, zeigt aber im Uebrigen dasselbe Verhalten wie bei Nothura.

Die Functionen, welche dieser Muskel bei den Rasores ausübt, sind dieselben wie bei den Natatores.

Der Subcutaneus abdominalis Wiedemann, Bauchhautmuskel

entspringt bei Nothura direct mittelst seiner Fasern, bei Gallus mit einer kurzen Sehne von der vorderen Kante des unteren Theils des $0 \mathrm{~s}$ pubis und läuft, gleich breit bleibend, anfangs unmittelbar neben der Aussenseite der Unterflurhälfte nach vorne. Auf dem hinteren Theil der Brust angekommen, wird er etwas schmäler, wendet sich von der Unterflur ab und dem Aste dieser Flur zu und inserirt sich theils an die innere, theils an die äussere Seite desselben. $\mathrm{Er}$ ist in seinem ganzen Verlauf nur lose an die ihn bedeckende Haut, fest dagegen mit der Aussenseite der Unterflur durch Bindegewebe verbunden. 
Bei Nothura und mânchen Hühnern fand ich den in Rede stehenden Muskel nur wenig, bei anderen dagegen wieder kräftig entwickelt.

Er verrichtet dieselben Functionen wie bei den Natatores und Grallatores.

Bei Gallus domesticus fand ich weiter noch eine Muskellage, die allerdings nur schwach entwickelt ist und auch, wie es mir scheint, je nach Alter und Geschlecht einen verschiedenen Grad der Ausbildung besitzen kann. Ich bezeichne sie mit

\section{Musculus gastro-lumbalis.}

Sie spannt sich in der Regel zwischen dem oberen Ende der Lendenflur und der unteren Hälfte der Aussenseite des Astes der Unterflur aus, doch beobachtete ich auch in einigen Fällen, dass eine Anzahl Fasern von der schon namhaft gemachten Stelle der Lendenflur an den hinter dem Ast der Unterflur liegenden Theil dieser Flur selbst hinliefen. Die Fasern dieser Lage, die zum Theil von dem Subcutaneus thoracicus überdeckt werden, liegen dicht neben einander und sind fest mit der darüberliegenden Haut verbunden. Contrahiren sie sich, so wird nicht blos die sie bedeckende Haut gefaltet, sondern auch die Haut der Brust und des Oberschenkels gespannt.

Was die Muskeln betrifft, die sich an die einzelnen Federn behufs deren Bewegung inseriren, so betrug bei Nothura ihre Zahl stets 4. Dieselbe Zahl fand ich auch bei den von mir untersuchten Exemplaren von Gallus domesticus, mit Ausnahme der Mitte des Rückens. An der letzteren Stelle inserirten sich an jede Feder der Rückenflur 6 Muskeln.

Nachdem ich die Hautmuskeln der Natatores, Grallatores und Rasores geschildert habe, glaube ich, wird es am Platze sein, eine kurze Beschreibung der Hautmuskeln, wie ich sie an einer mir von Herrn Geheimrath Prof. Dr. Leuckart freundlichst zur Untersuchung iiberlassenen Palamedea chavaria gefunden habe, folgen zu lassen. Ich fand bei diesem Vogel folgende Hautmuskeln :

Den Constrictor colli Owen.

"Triangularis juguli Wiedemann.

"Dermo-furcularis.

" Tensor cutis brachialis posterioris Magnus, oder Dermo-costalis Owen.

"Dermo-iliacus Owen.

\section{Constrictor colli Owen.}

Nur die Schicht, die ihren Ursprung vom Schädel nimmt, ist kräftig ausgebildet. Ihre Fasern entspringen an derselben Stelle wie bei den Schwimmvögeln, d. h. zum grössten Theil vom unteren Theil der Querleiste des Hinterhaupts und zum kleinen Theil von dem bei der zum Vergleich herbeigezogenen Gruppe näher bestimmten Fortsatz des Schläfenbeins. 
Von ihrer Ursprungsstelle aus laufen die Fasern bis zur Mitte des Halses fast geradlinig und unter Beibehaltung der ursprünglichen Breite nach hinten. Von dieser Stelle aus aber nimmt auf jeder Seite die Schicht an Breite etwas zu bis sie in in einem fast unmerklichen Bogen dem unteren Theil der Furcula zuläuft. Kurz ehe sie diese erreicht, wird sie wieder etwas schmäler. Sie löst dabei ihre Verbindung mit der sie bedeckenden Haut, obschon diese in ihrem Verlauf, mit Ausnahme einer kleinen Strecke an der Ursprungsstelle, eine sehr innige ist. Die auf beiden Seiten des Halses verlaufenden Fasern berühren sich weder auf dem Vorder- noch auf dem Hinterhals, sondern bleiben durch einen mehr oder minder breiten Zwischenraum von einander getrennt. Derselbe ist an beiden Seiten des Oberhalses, d. h. vorne und hinten, gleich breit, wird in der Mitte des Halses etwas schmäler, dann am unteren Theil desselben auf dem Hinterhalt wieder breiter, um endlich auf dem Vorderbals dagegen abermals schmäler zu endigen.

Die 2. Schicht des Constrictor colli fand ich bei dem von mir untersuchten Exemplar nur sehr wenig entwickelt, nämlich nur am obersten Drittel des Vorderhalses. Sie bestand aus einer Anzahl isolirter Fasern, die sich hauptsächlich unter demjenigen Theil der Haut ausbreiteten, welcher nicht von den Fasern des Subcutaneus colli berührt wurde.

\section{Der Triangularis juguli Wiedemann. Kehlhaut- muskel.}

Es ist dies ein Muskel, der in seiner Form viel Aehnlichkeit mit dem hintern kleineren Theil desselben Muskels bei den Natatores zeigt. Er entspringt wie bei einigen Gliedern der erwähnten Gruppe von dem unteren Rand des hinteren Fortsatzes des Unterkiefers, läuft in etwas schiefer Richtung nach vorne, der Mittellinie des Kinns zu, und geht erst zu beiden Seiten dieser Linie, etwas breiter werdend, eine innige Verbindung mit der ihn bedeckenden Haut ein. Doch inseriren sich die von den beiden Unterkieferhälften kommenden Fasern nicht an eine von der Spitze des Unterkiefers entspringenden Sehne, sondern sie bilden an der Stelle der Haut, an welcher sie zusammenstossen, eine Naht, die mit der schon mehrmals genannten Mittellinie zusammenfällt.

\section{Der Dermo-furcularis}

kommt von der Innenfläche der F ureula und zwar entspringt er unmittelbar neben dem oberen Ende der Insertionsstelle des S u bcutaneus colli. Seine Fasern differenziren sich gleich nach ihrem Ursprung in eine Anzahl Bündel, welche erst dem übrigen Theil des schon namhaft gemachten Knochens entlang laufen, sich dann der Mittellinie des Rückens zuwenden, dabei stark divergiren und sich an die Haut, die dem Vorderrücken und dem Hinterhals

Cab. Journ. f. Ornith. XXXII. Jahrg. No. 167 u. 168. Juli u. October 1884.23 
zur Seite der Wirbelsäule aufliegt und dem Rückgratrain der Natatores entsprechen würde, inseriren. Er scheint in seinem Verlaufe unter der Haut fest mit derselben verbunden zu sein.

\section{Dermo-iliacus Owen.}

Er nimmt mit einer kurzen Sehne von dem obern Fortsatz des 3. letzten Brustwirbels seinen Ursprung und läuft, immer gleich breit bleibend, in einem flachen Bogen nach vorne, um sich unmittelbar über den Fasern des Tensor cutis brachialis posterioris, mit denen er zum Theil verschmilzt, an eine Stelle der Haut, welche dem unteren Ende der Schulterflur anderer Vögel entsprechen würde, zu inseriren. Er ist fest mit der ihn bedeckenden Haut verbunden.

Tensor cutis brachialis posterioris Magnus. Dermocostalis Owen. Spanner der hinteren Flughaut.

Unter allen bei Palamedea vorkommenden Hautmuskeln ist der eben angeführte am mächtigsten entwickelt. Er entspringt mit einer kurzen aber breiten Sehne am Anfang des 2. Drittels der 3. untersten Rippe von deren vorderen Kante und behält während seines ganzen Verlaufs immer die gleiche Breite. Die Insertionsstelle ist theils die schon namhaft gemachte Stelle der Haut, die dem unteren Ende der Schulterflur entspricht, theils auch der ausserhalb dieser Stelle liegende Theil der hinteren Flughaut. An beide gehen gleich viele Fasern.

Die Zahl der Muskeln, welche an jede einzelne Feder sich inserirten, betrug in den meisten Fällen $4 ; 6$ fand ich nur an denjenigen Federn, die den vorderen Theil der Brust bekleideten, welche den Federn des Unterflurastes der Schwimmvögel analog waren, und ferner an den Federn des Oberschenkels.

Wie schon an einer anderen Stelle bemerkt wurde, sind auch die Dunen, die zwischen den Conturfedern auftreten, mit besonderen $\mathrm{zu}$ ihrer Bewegung dienenden Muskeln ausgestattet. Dieselben sind aber stets weniger entwickelt als diejenigen, die sich an die Conturfedern inseriren, und laufen unter den letzteren hinweg. Da nun die beiden genannten Arten von Federn regellos untereinander stehen und die Anzahl der Muskeln, welche sich an eine Dune inseriren, auch 4 beträgt, so erhält die Haut dadurch an ihrer Innenfläche ein ganz eigenthümliches Gepräge.

Wenn man die Schilderung der Hautmuskulatur von Palamedea mit der der Natatores vergleicht, so ergiebt sich, dass der Subcutaneus colli, der Dermo-furcularis und der Dermoiliacus bei beiden an gleicher Stelle entspringt, unter gleichen Strecken der Haut verläuft und an gleicher Stelle endigt, dass also Palamedea im Bezug auf die Ausbildnng der bei ihr vorkommenden Hautmuskeln den Natatores am nächsten steht. 


\section{Columbinae, Tauben.}

Untersucht wurden von mir Columba domestica, risoria und Goura coronata; gefunden wurden folgende Hautmuskeln:

Der Constrictor colli Owen.

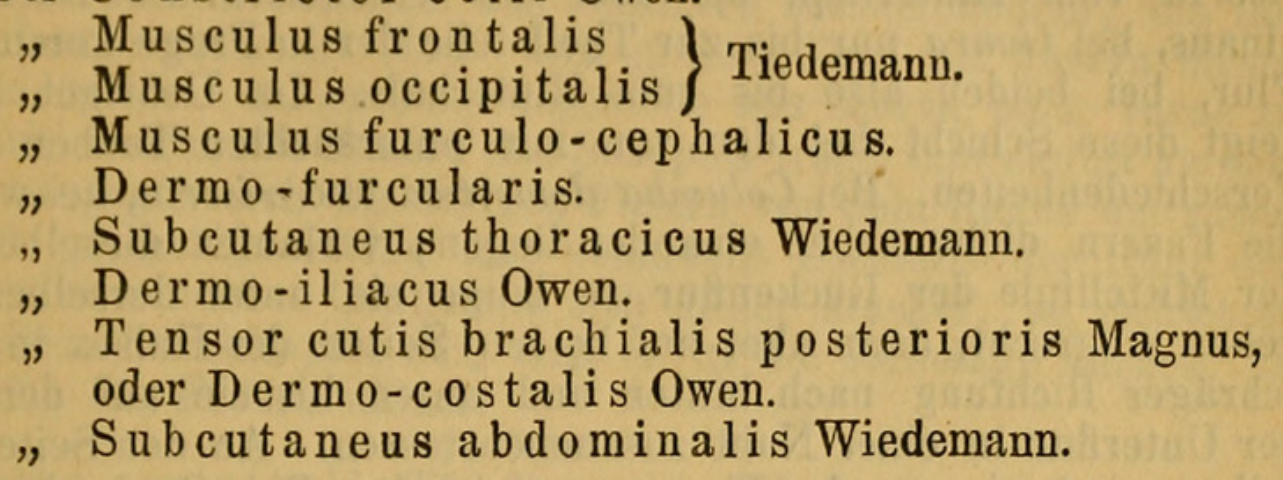

Der Constrictor colli Owen.

Die beiden Schichten dieses Muskels sind in ziemlich gleicher Weise entwickelt.

Die Fasern des Subcutane us colli entspringen bei Goura über der äusseren Ohröffinung bogenförmig neben dem Rande der Orbitalhöhle, bei Columba domestica und risoria ebenfalls über der schon erwähnten Oeffnung, aber am Rande der in Frage kommenden Höhle selbst. Bei allen 3 Vögeln zeigen die Fasern dieser Schicht in ihrem weiteren Verlauf ein ähnliches Verhalten wie bei den Rasores und Natatores, doch endigen dieselben nicht wie bei diesen beiden Ordnungen an dem unteren Theil der Furcula, sondern an einer in der Nähe derselben liegenden fascies des Musculus pectoralis major. Bogenförmig von der Ursprungszur Insertionsstelle verlaufend, kommen die Fasern auf der vorderen Hälfte des Halses bei Columba domestica und risoria zum grössten Theil unter die Rückenflur und nur ein kleiner Theil unter den Halsseitenrain und den äusseren Theil der Unterflur, bei Goura hingegen, bei welcher der oben genannte Rain kurz ist, nur unter die Rückenflur zu liegen. Auf der hinteren Hälfte des Halses dagegen verbreiten sich die Fasern bei Goura ausschliesslich unter der Unterflur, während bei Columba domestica und risoria auch ein kleiner Theil unter dem Halsseitenrain verläuft. Die auf beiden Seiten des Halses verlaufenden Fasern berühren sich nur am Oberhals auf der Mittellinie der Rückenflur in einer Strecke, welche bei Columba risoria und domestica nur kurz, bei Goura relativ etwas länger ist.

Mit Ausnahme einer kurzen Strecke an ihrer Ursprungs- und Insertionsstelle sind die Fasern dieser Schicht ebenso wie bei den Natatores und Rasores fest mit der sie bedeckenden Haut und der sie überlagernden 2. Schicht des Constrictor colli durch Bindegewebe verbunden.

Die 2. Schicht des in Rede stehenden Muskels breitet sich beiden von mir untersuchten Tauben an dem grössten Theil des 
Halses aus, nämlich auf der vordern Seite vom hinteren Ende des Kehlhautmuskels, also vom Anfang des Halses, bis zur Theilstelle der Unterflur in 2 Hälften, bis zum Hinterhals. Auf der Rïckenflur erstreckt sich diese Schicht bei Columba domestica und risoria vom Hinterkopf bis über die Theilstelle der Rückenflur hinaus, bei Goura nur bis zur Theilstelle der in Frage kommenden Flur, bei beiden also bis zum Hinterhals. Im Uebrigen jedoch zeigt diese Schicht bei den von mir untersuchten Tauben einige Verschiedenheiten. Bei Columba domestica und risoria, bei welchen die Fasern dicht neben einander liegen, verlaufen dieselben von der Mittellinie der Rückenflur so lange sie unter derselben hingehen wagrecht, dann aber auf beiden Seiten des Halses in etwas schräger Richtung nach hinten und unten bis sie auf der Mitte der Unterflur in einer Naht zusammenstossen. An den Seiten derselben sind sie am kräftigsten entwickelt. Bei Goura hingegen fand ich die Fasern auf dem Hinterhals am kräftigsten ausgebildet; auch schlugen nicht alle in ihrem Verlaufe, nur ausgenommen bleibt die Rückenflur, unter der sie ebenfalls wagrecht verliefen, dieselbe Richtung ein. Nämlich blos am oberen Halstheil zeigten die Fasern dasselbe Verhalten wie bei Columba, während sie am Mittelhals fast geradlinig vom Hinter- zum Vorderhals liefen und weiter nach hinten sogar die entgegengesetzte Richtung einschlugen, indem sie von hinten nach vorne und unten verliefen. Auf der Mitte der Unterflur bilden sie bei Goura keine Naht.

In allen Fällen sind die Fasern dieser Schicht ebenfalls fest mit der sie bedeckenden Haut durch Bindegewebe verbunden.

Der Constrictor colli wird im Allgemeinen dieselben Functionen wie bei den Natatores und Rasores ausüben, doch ist er vielleicht nicht im Stande, in dem Maasse wie bei den zum Vergleich herbeigezogenen Ordnungen auf den Kropf einzuwirken.

\section{Triangularis juguli Wiedemann. Kehlhautmuskel.}

Er zeigt viel Aehnlichkeit mit demjenigen der Rasores und einiger Natatores, indem er auch von 2 verschiedenen Stellen der Unterkieferhälfte entspringt. Der Haupttheil der Fasern kommt von der Innenfläche des Os dentale, ein anderer Theil von der Aussenfläche des Unterkieferrandes. Die Fasern des ersten Theils laufen von ihrer Ursprungsstelle in etwas schräger Richtung nach hinten und inseriren sich an eine wie bei den Rasores gestaltete Sehne; die Fasern des anderen Theils hingegen laufen grösstentheils etwas nach vorne gerichtet der Sehne zu und nur die hintersten schlagen in ihrem Verlaufe eine gerade Richtung von der Ursprungs- zur Insertionsstelle ein. Die Fasern beider Theile gehen gleich nach ihrer Ursprungsstelle eine innige Verbindung mit der sie bedeckenden Haut ein; sie breiten sich unter der Haut des Kinns aus und verrichten dieselben Functionen wie bei den Natatores und Rasores. 
Ueber die Hautmuskeln der Vögel etc.

Musculus frontalis Tiedemann. Stirnhautmuskel.

Diesen Muskel fand ich nur bei Goura; in seinem Verhalten zeigt er viel Aehnlichkeit mit dem gleichnamigen Muskel der Rasores. Er entspringt wie bei diesen am oberen Rand der Augenhöhle und besteht ebenfalls aus einzelnen Muskelbündeln, die mit Sehnenfasern vermengt sind. Der grösste Theil der Fasern dieses Muskels läuft von seiner Ursprungsstelle aus schräg nach vorne zu der Haut, welche die Federn des Schopfes trägt, und endigt an derselben, wogegen sich die übrigen Fasern von dem Rande der schon namhaft gemachten Höhle fast senkrecht ebenfalls der Haut des Schopfes zuwenden. Contrahirt sich dieser Muskel, so richtet er die Federn des Schopfes auf, tritt er in die Ruhelage zurück, so legen sich die Federn nieder.

Musculus occipitalis Tiedemann. Hinterhauptsmuskel.

Namentlich stark ist dieser Muskel bei Columba risoria entwickelt. Hier entspringt er auf beiden Seiten des Kopfes von dem mittleren Theil der Querleiste des Hinterhauptbeins, läuft nach vorne und inserirt sich an die Haut, die dem Scheitel aufliegt. Contrahirt er sich, so spannt er die Stirn- und Vorderhauptshaut, faltet die Haut, die den Scheitel bedeckt, und vielleicht zum grössten Theil auch diejenige, welche dem Hinterhaupte aufliegt. Er sträubt somit die Federn des Oberkopfes.

\section{Der Musculus furculo-cephalicus}

nimmt auf jeder Körperseite seinen Ursprung von der Innenfläche der Furcula und zwar vom Ende des untersten Drittels und läuft dann unter dem Kropf, ohne jedoch eine Verbindung mit demselben einzugehen, nach unten bis er die Spitze der Furcula erreicht hat. Von dieser Stelle aus wendet er sich nach vorne, nimmt an Breite zu und geht bis zur Theilstelle der Unterflur, neben den Fasern des Subcutaneus colli liegend, eine innige Verbindung mit dem inneren Theil der Hälfte der schon genannten Flur ein. Von der ebenfalls schon näher bestimmten Stelle der Unterflur aus laufen die Fasern, die 2. Schicht des Constrictor bedeckend, unter dieser Flur, ebenfalls fest mit ihr verbunden, bis zum vorderen Theil des Halses. Dann lösen sie ihre Verbindung. mit der Haut und differenziren sich auf jeder Halsseite in 2 schmale Muskeln, von welchen der innere sich an das Zungenbein unmittelbar vor der Abgangsstelle der Hörner, der andere an den neben der Unterkieferhälfte liegenden Theil der Haut der Mundhöhle ansetzt.

Dieser Muskel unterstützt in seiner Function als Hautmuskel den Constrictor colli, indem er die Haut, an welche er befestigt ist, faltet und die in ihr sitzenden Federn sträubt. Gleichzeitig wird er aber einen Druck auf den Kropf ausüben und die Mundhöhle vergrössern. 


\section{Dermo-furcularis.}

Sowohl bei Columba domestica und risoria als auch bei Goura entspringt derselbe oberhalb des vorigen Muskels von der Innenfläche der Furcula, läuft neben derselben nach dem Rücken zu und wendet sich dann zur Rückenflur. Bei den ersten beiden der oben genannten Tauben, bei denen die Fasern sich nicht in einzelne Bündel gruppiren, inserirt sich der Haupttheil auf der Grenze zwischen Hals und Brust an den Anfangstheil der beiden Hälften der Rückenflur, der übrig bleibende Rest aber an die noch ungetheilte Partie derselben. Bei Goura wird gerade das Gegentheil beobachtet. In allen Fällen sind die Fasern dieses Muskels, soweit sie unter der Haut verlaufen, fest mit derselben verbunden. Die Wirkung des Muskels ist dieselbe wie bei den übrigen Ordnungen.

\section{Subcutaneus thoracicus W iedemann. Brusthaut-} muskel.

Es ist dies ein Muskel, der bei allen von mir untersuchten Tauben von derselben Stelle, nämlich von dem untern äusseren Ende der Sehne des grossen Brustmuskels kommt und, fest mit der ihn bedeckenden Haut verbunden, über denselben hinweg nach hinten und unten läuft. Auf diesem Verlaufe behält er aber nicht immer die gleiche Gestalt. Er nimmt etwas an Breite zu, wie dies namentlich bei Columba domesiica und risoria zu beobachten ist. Bei Goura endigt der Muskel an dem unteren äusseren Theil des 2. Astes der Unterflur; bei den übrigen Tauben, bei denen kein Unterflurast auftritt, an einer diesem Ast anderer Vögel entsprechenden Stelle der Flur selbst. Seine Function ist dieselbe wie bei den anderen Vogelordnungen.

\section{Den Dermo-iliacus Owen}

fand ich bei den vor mir untersuchten Tauben nicht immer in gleicher Weise entwickelt. Bei Goura beobachtete ich nur den Theil, der unter der Rïickenflur nach vorne verläuft und am Mittelrücken endigt, bei Columba domestica und risoria hingegen die Partie, welche sich an das untere Ende der Schulterflur inserirt.

Der erste Theil entspringt bei Goura von dem oberen Fortsatz des letzten Brustwirbels, läuft auf jeder Körperseite unter der Rückenflurhälfte und eine Strecke lang auch unter dem Rumpfseitenrain nach vorne, und endigt, nachdem seine Fasern sich fächerförmig ausgebreitet haben, auf dem Mittelrücken. Die Fasern inseriren sich theils an die Aussenseite der Rückenflur, theils an den Rumpfseitenrain, zum kleinen Theil auch an die Innenseite der Schulterflur.

Diese Muskelpartie wird dieselben Functionen ausüben wie der ihr entsprechende Theil des Dermo-iliacus bei den Grallatores und Rasores, zumal sie auch auf ihrem ganzen Verlaufe fest mit der sie bedeckenden Haut verbunden ist. 
Der Theil des Dermo-iliacus, der bei Columba domestica und risoria auftritt, entspringt von dem Fortsatz des 3 . und manchmal auch des 4 . hintersten Brustwirbels, läuft bogenförmig unter der Rückenflur und dem Rumpfseitenrain der Schulterflur zu und inserirt sich neben den Fasern des Tensor cutis brachialis posterioris an das untere Ende derselben. Er ist schmal und behält auf seinem ganzen Verlaufe, auf welchem er mit den ihn bedeckenden Haut fest verbunden ist, dieselbe Breite.

Er übt dieselbe Function wie bei den Natatores aus.

Tensor cutis brachialis posterioris Magnus, Dermocostalis Owen. Spannerder hinteren Flughaut.

Dieser bandförmige Muskel entspringt bei den von mir untersuchten Tauben in etwas verschiedener Weise. Bei Goura nimmt der Hauptheil der Fasern mittelst einer kurzen Sehne eine kleine Strecke unter der Abgangsstelle des Proc. unc. von der vorderen Kante der 2., der übrige Theil an gleicher Stelle von der Aussenfläche der 3. untersten Rippe seinen Ursprung. Bei Columba domestica und risoria hingegen entspringt dieser Muskel mit 3 Köpfen an gleicher Stelle der Rippen, und zwar der Haupttheil der Fasern von der Aussenseite der 3., die übrigen dagegen theils mit einer kurzen Sehne von der vorderen Kante der 2., theils direct mittelst der Fasern von der Aussenfläche der 4. untersten Rippe.

Die Vereinigung der getrennt entspringenden Köpfe zu einem bandförmigen, auf seinem Verlaufe etwas schmäler werdenden, Muskel geschieht kurz nach ihrem Ursprung. Der grösste Theil der Fasern endigt an dem unteren Ende der Schulterflur, der übrige Theil an dem ausserhalb dieser Flur liegenden Theil der hinteren Flughaut. In seinem übrigen übrigen Verhalten und in der Ausübung seiner Functionen stimmt er ganz mit dem der Natatores überein.

\section{Subcutaneus abdominalis Wiedemann. Bauchhaut-} muskel.

Er kommt bei allen von mir untersuchten Tauben mit einer kurzen aber breiten Sehne von der vordern Kante des unteren Theils des $O s$ pubis, zeigt aber in seinem weiteren Verlauf, wahrscheinlich in Folge der verschiedenen Ausbildung der Fluren, bei Goura ein etwas anderes Verhalten als bei Columba domestica und risoria. Bei den letzteren läuft er von seiner Ursprungsstelle aus neben der Aussenseite der Unterflurhälfte dabei etwas schmaler werdend nach vorne und inserirt sich in gleicher Höhe mit dem unteren hinteren Randende des M. pectoralis major an den kräftig entwickelten Theil der Unterflur. Bei Goura hingegen, bei welcher die in Frage kommende Flur 3 Aeste ausschickt, von denen jedoch nur der mittelste dem Ast der Unterflur anderer Vögel entspricht, läuft der in Rede stehende Muskel nur eine Strecke lang nach seiner Ursprungsstelle neben der Aussenseite der schon er- 
wähnten Flur, biegt aber dann von ihr ab, wendet sich dem 2. Ast $\mathrm{zu}$ und inserirt sich, nachdem er in eine bandförmige Sehne übergegangen ist, an das untere Ende desselben. Er ist in allen Fällen ziemlich fest an die Unterflur, lose dagegen nur an die bedeckende Haut befestigt.

Er übt denselben Effect wie bei den Rasores, Grallatores und Natatores aus.

Bei Goura fand ich regelmässig 4 Muskeln, welche sich an jede einzelne Feder inserirten. Auch bei Columba domestica und risoria war dies mit Ausnahme derjenigen Federn der Fall, die sich am Mittelhals und auf dem Rücken befanden. An die Federn, die auf den eben bezeichnten Stellen auftraten, inserirten sich in den meisten Fällen 6 Muskeln.

\section{Scansores, Klettervo̊gel.}

Untersucht habe ich von dieser Ordnung leider nur Picus major und zum Theil auch Picus viridis; gefunden habe ich folgende Muskeln :

Den Constrictor colli Owen.

"Dermo-furcularis.

"Musculus furculo-cephalicus.

"Subcutaneus thoracicus Wiedemann.

"Tensor cutis brachialis posterioris Magnus,

" oder Dermo-costalis Owen.

"Subcutaneus abdominalis Wiedemann.

"Musculus humero-spinalis.

\section{Constrictor colli Owen.}

Die beiden Schichten dieses Muskels fand ich bei Picus major kräftig entwickelt, die Fasern der ersten Schicht, des Subcutaneus colli, entspringen von der Mitte der Leiste des Schläfenbeins, also in ziemlicher Entfernung von der Orbitalhöhle, und laufen fast geradlinig und in gleicher Breite bis zur Mitte des Halses. Von dieser Stelle aus trennt sich der kleinere Theil derselben, diejenigen umfassend, die am weitesten am Vorderhals liegen, läuft in einem flachen Bogen der Aussenseite der Unterflurhälfte zu und erreicht dieselbe eine kleine Strecke unterhalb der Differenzirung'sstelle der schon erwähnten Flur in 2 Hälften, genau an der Stelle, an welcher der Musculus furculo-cephalicus an die Unterflurhälfte befestigt ist. In Form eines bandförmigen Muskels laufen dann die Fasern eine kurze Strecke an der Aussenseite derselben hin, wenden sich aber bald dem oberen Ende der grössern äussern Schulterflur zu. Ein Theil endigt hier, während der andere Theil sehnig wird, dem Spanner der vorderen Flughaut zuläuft und mit demselben sich vereinigt. Der Rest der Fasern läuft von der schon genannten Stelle des Halses unter den äusseren Federreihen der Rückenflur nach hinten bis zu der Stelle, 
an der die Flur anfängt, anf ihrem Verlauf gleiche Breite einzuhalten. Von dieser Stelle aus erleidet auch die sie begleitende Muskelpartie eine Veränderung; ihre Fasern bilden auf jeder Körperseite einen schmalen, bandförmigen Muskel, welcher an der Seite der in Rede stehenden Flur nach hinten verläuft und unterhalb des Dermo-furcularis, der an die Aussenseite der Rückenflur sich inserirt, in eine Sehne übergeht, dann aber seine vorige Form wieder annimmt und beibehält bis zu dem Punkte, an dem die Rückenflur endigt, um eine Strecke weiter hinten in Gestalt eines 2 lappigen Sattels von Neuem aufzutreten. Nachdem der Muskel von der ersten Stelle aus an Breite etwas zugenommen hat, läuft er in einem flachen Bogen (dessen convexe Seite der Rïckenflur zugekehrt ist) über die Mitte der Sattelhälfte nach hinten bis zum $\mathrm{O}$ s ilium, an dessen oberen Rand er sich inserirt. Die Fasern dieses Muskels sind durch Bindegewebe mit der sie bedeckenden Haut und, soweit sie neben Unter- und Rïckenfiur verlaufen, auch mit der Aussenseite derselben verbunden. Da auch die Fasern vor ihrer Trennung in 2 Partien auf ihrem geradlinigen Verlauf nach hinten zum grössten Theil unter den Halsseitenrain und zum kleinen Theil unter die Rückentlur zu liegen kommen, so verläuft der Muskel hauptsächlich an der Seite der eben genannten Flur, während nur ein kleiner Theil der Fasern an der Schulterflur und gar keine an der Unterflur endigen.

Die 2. Schicht des Constrictor colli breitet sich nur unter der Haut der oberen Halshälfte aus, ist aber sehr kräftig entwickelt und bildet eine förmliche Muskelscheide. Die Fasern derselben fangen an der Mittellinie der Rückenflur an, verlaufen, soweit sie unter diese Flur zu liegen kommen, beinahe wagrecht, dann aber in schiefer Richtung nach hinten und unten und bilden, soweit sie auf die ungetheilte Unterflur treffen, eine Naht, welche mit der Mittellinie der Flur zusammenfällt, endigen aber schon an der Aussenseite, wenn sie auf die Unterflurhälfte stossen.

Die Fasern dieser Schicht liegen dicht neben einander und sind auf ihrem Verlauf fest mit der sie bedeckenden Haut verbunden.

Zieht sich der Constrictor colli zusammen, so faltet er nicht nur den grössten Theil der Halshaut und unterstützt dadurch den Subcutaneus abdominalis, sondern er faltet zugleich auch die Haut, welche dem Rücken aufliegt, und sträubt somit ebenfalls die Federn des Theils der Rückenflur, der die Brustregion bedeckt.

Der in Rede stehende Muskel übernimmt also gleichsam die Functionen des Dermo-transversalis und auch zum Theil diejenigen des Dermo-iliacus wie dieser bei den Rasores und Grallatares vorkommt. 


\section{Der Dermo-furcularis}

ist ein schmaler, bandförmiger Muskel, der von der Innenfläche der oberen Hälfte ber Furcula entspringt und neben diesem Knochen hinläuft. Am oberen Ende desselben angekommen, wendet er sich, unter dem dort befindlichen Theil des Rumpfseitenrains hingehend, ziemlich geradlinig der Rückenflur zu, wird etwas breiter und endigt, nachdem er vorher den Zweig des Subcutaneus colli, welcher an das Os ilium sich ansetzt, überstrichen hat, an der Aussenseite des Rückenflurtheils, der den Hinterhals bedeckt. Er ist, soweit er unter der Haut verläuft, nur lose an dieselbe befestigt und verrichtet genau dieselbe Function wie bei den anderen Vogelordnungen.

\section{Musculus furculo-cephalicus.}

Er ist ebenfalls ein schmaler, bandförmiger Muskel, kommt von dem oberen Ende der untersten Hälfte der Furcula und läuft in der schon genannten Form nach vorne, bis er sich an die Haut befestigt. Diese Verbindung tritt eine ziemliche Strecke unterhalb der Theilstelle der Unterflur ein, und zwar ist es auf jeder Halsseite die Unterflurhälfte, an welche er sich anheftet. Auf dieser Strecke, die sowohl bei Picus viridis als auch bei Picus major nur sehr kurz ist, wird der Muskel etwas breiter, um dann am Ende derselben die ursprüngliche Form wieder anzunehmen, nach vorne zu laufen und sich an den Körper des Zungenbeins zu inseriren.

Der in Rede stehende Muskel wird keinen bedeutenden Einfluss auf die äussere Haut ausüben; höchstens wird er die Strecke derselben, die zwischen seiner Ursprungsstelle an der Furcula und seiner Verbindungsstelle mit der Unterflurhälfte liegt, etwas falten und so die in ihr sitzenden Federn sträuben. Ausserdem wird er auch an dem Zurückziehen der in so hohem Grade vorschnellbaren Zunge theilnehmen.

Subcutaneus thoracicus Wiedemann. Brusthaut$\mathrm{muskel}$.

Dieser Muskel entspringt sowohl bei Picus major als auch bei Picus viridis unmittelbar neben dem oberen Ende der Sehne

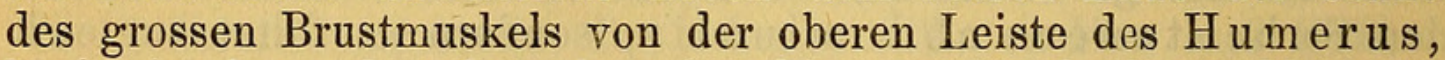
läuft eine kurze Strecke neben dem hinteren Rande dieses Muskels, dann aber über ihn selbst schräg nach hinten und unten unter die vom Aussenast der Unterflur zur Schulterflur hingehenden Federreihen und inserirt sich, etwas breiter werdend, an das untere Ende des eben genannten Astes. Er hat eine bandförmige Gestalt und ist, soweit er über den grossen Brustmuskel verläuft, fest mit der ihn bedeckenden Haut durch Bindegewebe verbunden.

Die Functionen, welche dieser Muskel bei den Spechten verrichtet, sind dieselben wie bei den anderen Vögeln. 
Tensoreutisbrachialis posterioris Magnus, Dermocostalis Owen. Spannerder hinteren Flughaut.

Der Knochen, von dem dieser Muskel entspringt, ist die 5. unterste Rippe. Der Ursprung geschieht sowohl bei Picus major als auch bei Picus viridis mit einer kurzen Sehne; bei dem ersteren unmittelbar unter dẹ Abgangsstelle des Proc. unc. vom hinteren Rande, bei Picus viridis hingegen an einer etwas tiefer gelegenen Stelle von der Mitte der Aussenfläche der schon namhaft gemachten Rippe. In beiden Fällen hat der Muskel eine bandförmige Gestalt, zeigt dasselbe Verhalten wie bei allen anderen Vögeln und endigt mit der Hälfte seiner Fasern an dem unteren Ende der Schulterflur, während die andere Hälfte, nachdem sie die bei allen Vögeln auftretende Umwandlung erlitten bat, an den ausserhalb der Schulterflur liegenden Theil der hinteren Flughaut geht.

Er verrichtet die gleichen Functionen wie bei den übrigen Vögeln auch bei den Spechten.

Subcutaneus abdominalis Wiedemann. Bauchbautmuskel.

In Vergleich zu den übrigen bei Picus major vorkommenden Hautmuskeln ist der eben angeführte sehr mächtig entwickelt. $\mathrm{Er}$ entspringt mit einer kurzen Sehne von der vordern Kante des unteren Theils des $\mathrm{Os}$ pubis. Von seiner Ursprungsstelle aus läuft er eine Strecke lang neben der Aussenseite der Unterflurhälfte nach vorne, wendet sich aber dann dem Ast der Unterflur zu und endigt an dem unteren Ende desselben. Auf seinem Verlaufe behält er immer dieselbe Form und ist fest durch Bindegewebe mit der Aussenseite der schon mehrmals erwähnten Flur, lose dagegen mit der ihn bedeckenden Haut verbunden.

Er wirkt auch bei der in Rede stehenden Vogelgruppe wie bei allen anderen Vögeln.

\section{Musculus humero-spinalis.}

Er repräsentirt keinen schmalen, bandförmigen Muskel, sondern eine breite Muskellage, die sich sowohl zwischen der der Riickenflur zugekehrten Seite der äusseren als auch dem unteren Theil der inneren Schulterflur und dem gegenüber liegenden Theil der Aussenseite der Rüickenflur ausspannt. Die am weitesten hinten gelegenen Fasern dieser Schicht verlaufen von der Riickenflur in schiefer Richtung unter dem Rumpfseitenrain der Schulterffur zu, die mittleren Fasern dagegegen wagrecht und die vordersten, welche sich an das untere Ende der inneren Schulterflur inseriren, kommen anfangs neben die mittleren zu liegen, wenden sich aber dann der schon genannten Stelle zu, so dass zwischen der inneren und äusseren Schulterflur ein kleiner Raum entsteht, der nicht von Fasern überstrichen wird. 
Die Fasern dieser Schicht sind fest mit der sie bedeckenden Haut verbunden und sind im Stande, die Haut zwischen Rückenund Schulterflur zu falten und vielleicht auch die letztere Flur der ersteren zu nähern. Bei den von mir untersuchten Spechten betrug die Anzahl der Muskeln, welche sich an die einzelnen Federn inserirten, stets 4 .

\section{Passeres, Gangvögel.}

Von den Mitgliedern dieser Ordnung untersuchte ich: Corvus corone, C. cornix, C. pica, C. glandarius, Sturnus vulgaris, Turdus merula, T. musicus, Fringilla coelebs, Fr. cannabina, Loxia curvirostra, Musicapa grisola, Passer domesticus, Alauda arvensis, P.arus coeruleus und zum Theil auch Cypselus apus. muskeln :

Ich fand bei allem eben aufgezählten Vögeln folgende Haut-

Den Constrictor colli Owen.

"Dermo-furcularis.

" Musculus furculo-cephalicus.

"Subcutaneus thoracicus Wiedemann.

"Tensor cutis brachialis posterioris Magnus,

" oder Dermo-costalis Owen.

"Subcutaneus abdominalis Wiedemann.

\section{Constrictor colli Owen.}

Beide Schichten dieses Muskels sind ebenso wie bei den von mir untersuchten Scansores kräftig ausgebildet.

Die Fasern des Subcutaneus colli entspringen bei den genannten Arten mit Ausnahme von Cypselus stets senkrecht über der äusseren Ohröffnung in mehr oder minder grosser Entfernung von der Orbitalhöhle. Bei den Corvidae, bei denen die Fasern nicht über, sondern hinter einander ihren Ursprung vom Schädel nehmen, liegen natürlich nur die vordersten in unmittelbarer Nähe der schon genannten Höhle; bei den übrigen Passeres hingegen entspringen die Fasern uber einander am Rande der in Frage kommenden Höhle und liegen daher alle derselben gleich nahe. Eine Ausnahme macht, wie schon beiläufig erwähnt, nur Cypselus; bei ihr kommt dieser Muskel in Gestalt einer Schnur von dem vorderen Ende des Os frontale und läuft in einer rinnenförmigen Ausbuchtung des Augenhöhlenrandes nach hinten bis er an eine Stelle kommt, die ziemlich genau senkrecht über der äusseren Ohröffinung liegt; von dieser Stelle aus hält der Muskel dann auch bei Cypselus das gewöhnliche Verhalten ein. Die Fasern dieser Muskelschichten zeigen im Bezug auf ihren Verlauf und ihr Verbreitungsgebiet viel Uebereinstimmung mit dem gleichnamigen Muskel der Spechte. Von ihrer Ursprungsstelle aus laufen sie wie bei der letzteren Ordnung geradlinig, doch dabei 
etwas an Breite zunehmend, nach hinten und kommen auf der oberen Hälfte des Halses unter den Halsseitenrain und einen bald grösseren, bald kleineren Theil der Rückenflur zu liegen. Relativ am grössten ist der von Fasern dieser Schicht überstrichene Theil dieser Flur bei Loxia, Muscicapa und Corvus glandarius, bei ihnen bleibt nur ein an der Seite der Mittellinie liegender schmaler Raum frei, während bei den anderen nur eine kleine Portion der Fasern unter die äusseren Federreihen der in Rede stehenden Flur zu liegen kommt.

Am hintersten Theil der oberen Halshälfte differenziren sich die Fasern in 2 nach verschiedenen Richtungen verlaufende Partien, von denen wie bei den Spechten die eine der Unterflur sich zuwendet, die andere dagegen unter der Rückenflur weiter verläuft. Die letztere Partie ist stets die kleinere, denn sie umfasst ungefähr den dritten Theil der gesammten Fasermasse. Sie bildet einen schmalen Muskel, der auf jeder Körperhälfte an der Aussenseite der Rückenflur, durch Bindegewebe mit ihr fest verbunden, nach hinten läuft bis zu der Stelle, an welcher der D e r m o - f u r c u la ris ihn überstreicht und sich an die Aussenseite derselben Flur inserirt. Von dieser Stelle aus wird sowohl seine Befestigung mit der Flur etwas gelockert als auch seine Richtung etwas geändert. Er verläuft nun nicht mehr dicht neben, sondern in einiger Entfernung von der Flur nach hinten und fängt kurz vor dem Sattel an, etwas breiter zu werden. Die Breitenzunahme, verbunden mit einer wieder innigen Befestigung des Muskels mit der ihn bedeckenden Haut, dauert auf seinem ganzen Verlauf unter dem Sattel der Rückenflur bis zu seiner Insertion am $0 \mathrm{~s}$ ili u m fort. Die Insertionsstelle selbst liegt aber bei den von mir untersuchten Passeres nicht immer an demselben Theile des eben genannten Knochens. Bei den Turdidae endigt der Muskel am vorderen Rande des Os ilium, bei Muscicapa neben der Wirbelsäule unmittelbar vor den vordersten Fasern der Musculus glutaeus major und bei den übrigen Passeres an verschiedenen Stellen des zwischen den beiden eben genannten Punkten liegenden Theils dieses Knochens. Der Haupttheil des Subc. colli wendet sich, indem seine Fasern ebenfalls etwas convergiren und unter dem Halsseitenrain verlaufen der Aussenseite der Unterflur zu. Bei den Corvidae erreicht er dieselben unmittelbar hinter der Theilungsstelle der Flur, bei den übrigen Passeres an einem noch etwas weiter nach hinten gelegenen Punkt. Bei beiden aber läuft dann die Muskelpartie neben und zum Theil auch unter dem äusseren Theil der Unterflurhälfte nach hinten bis zum Ende des Halses. Dort endigt sie bei den Corvidae mit einem kleinen Theile, bei den übrigen Passeres mit dem Haupttheil der Fasern an derselben. Die iibrigen Fasern aber, bald einen kleinen, bald einen grossen Theil des Subc. colli ausmachend, wenden sich dem oberen Ende der Schulterflur zu und verlieren sich dort zum Theil, während die anderen in eine Sehne 
übergehen, welche dem Spanner der vorderen Flughaut zuläuft und mit der Sehne desselben sich vereinigt.

Die Fasern dieser Muskelschicht sind, abgesehen von einer kleinen Strecke an ihrer Ursprung:sstelle und einer kurzen Strecke auf dem Rücken, fest mit der sie bedeckenden Haut und, soweit sie neben der Unter- und Rückenflur verlaufen, auch mit diesen durch Bindegewebe verbunden.

Die 2. Schicht des Constrictor colli ist, wie schon erwähnt, ebenfalls kräftig entwickelt und breitet sich wie bei den Picidae nur unter der Haut der oberen Halshälfte aus. Sie bildet eine förmliche Muskelscheide, deren Fasern wie bei der zum Vergleich herbeigezogenen Familie auf der Mitte der Rückenflur anfangen, an der Seite des Halses verlaufen, und soweit sie auf die ungetheilte Unterflur treffen, eine Naht bilden, die mit der Mittellinie der Flur zusammenfällt. Hingegen endigen die Fasern schon an der Aussenseite der in Frage kommenden Flur, wenn sie auf die beiden Hälften derselben treffen. Obwohl wie bei den Picidae auch bei allen Passeres die Fasern, so lange sie unter die Rückenflur zu liegen kommen, ziemlich wagrecht verlaufen, schlagen sie doch auf ihrem weiteren Verlauf verschiedene Richtungen ein; die vordersten verlaufen genau in der Weise wie sämmtliche Fasern dieser Schicht bei Picus, die mittelsten dagegen gehen geradlinig und die hintersten in einem flachen Bogen (dessen convexe Seite nach vorne gekehrt ist) von der Rücken- zur Unterflur. Sämmtliche Fasern sind fest mit der dariiber liegenden Haut verbunden. Der Constrictor wirkt, in Folge der Uebereinstimmung seiner Form und des Verlaufs seiner Fasern bei allen Passeres mit dem der Picidae, auch im gleicher Weise wie bei den letzteren.

Der Dermo-furcularis

entspringt bei allen Passeres stets oberhalb des Musc. furculoc ephalicus von der Innenfläche der Furcula, bei den Corvidae vom Endtheil der unteren oder Anfangstheil der oberen Hälfte, bei den übrigen an einer noch etwas höher gelegenen Stelle. Von seiner Ursprungsstelle aus läuft er an der Innenseite des Knochens bis zum hinteren Ende desselben, wendet sich dann fast geradlinig der Rïckenflur zu und endigt, den Ast des Sub. colli, welcher neben derselben Flur nach hinten verläuft, überstreichend, an der Aussenseite des Theils, der dem Unterhals aufliegt.

Die Strecke, an der dieser Muskel sich inserirt, ist nicht bei allen Passeres gleich gross, weil er nicht bei allen das gleiche Verhalten zeigt. Bei Passer, Sturnus, Fringilla, Turdus und Loxia verhält er sich ähnlich wie bei den Picidae; seine Fasern gruppiren sich nicht $\mathrm{zu}$ isolirt verlaufenden Muskelbündeln, sondern bilden einen schmalen, bandförmigen Muskel, der nur kurz vor seiner Insertionsstelle etwas an Breite zunimmt. Die Strecke, an die er sich inserirt, ist daher bei diesen Vögeln auch nicht viel 
breiter als der Muskel selbst. Anders gestaltet sich aber das Verhältniss bei Parus coeruleus, Cypselus und den Corvidae. Bei ihnen differenziren sich die Fasern gleich nach ihrer Ursprungsstelle zu einer Anzahl Muskelbündel, die in ihrem Verlaufe nach der Rüekenflur mehr oder weniger divergiren. In diesem Falle wird natürlich eine grössere Strecke der Rückenflur, nämlich der Theil, der dem Unterhals und Vorderriicken aufliegt, von ihnen getroffen.

In beiden Fällen aber, mögen die Fasern in Form eines schmalen Bandes, oder als isolirte Muskelbündel verlaufen, sind sie in ihrem Verlaufe unter der Haut nur lose an dieselbe befestigt. Der Effect, welchen dieser Muskel bei den Passeres ausübt, ist derselbe wie bei allen anderen Vögeln.

Musculus furculo-cephalicus.

Mit Ausnahme von Cypselus und den Corvidae übt dieser Muskel bei allen von mir untersuchten Passeres in demselben Masse wie bei den Picidae die Function eines Hautmuskels aus. Seine Ursprungsstelle liegt aber in allen Fällen, mit Ausnahme von Cypselus, bei der er von der Mitte der F u r cu l a entspringt, tiefer als bei den Spechten. Bei den Corvidae kommt derselbe vom Ende des untersten Drittels oder Viertels, bei den übrigen Passeres von den unmittelbar neben der Vereinigungsstelle der beiden Hälften liegenden Theil (Loxia, Fringilla coelebs und cannabina) oder von dem Ligamentum sterno-furculare (Sturnus vulg., Turdus musicus), oder endlich gar von dem vorderen Ende der Crista des Sternums (Muscicapa grisola). Was seinen Verlauf anbetrifft, so verhält er sich bei allen Passeres ausser bei Cypselus und den Corvidae, genau so wie bei den Picidae. Bei den Passeres aber, die eine Ausnahme machen, verbindet sich der Muskel gleich nach seiner Ursprungsstelle mit der Unterflurbälfte. Diese Verbindung von Muskel und Flur erstreckt sich bei den Corvidae bis zur Theilstelle der Unterflur, bei Cypselus bis eine kurze Strecke unterhalb derselben. Dabei wird zugleich der Muskel etwas breiter. Vom Ende der Verbindungsstrecke an verhält er sich aber dann genau wie bei den übrigen Gliedern der in Rede stehenden Ordnung, $d$. h. er nimmt seine ursprïngliche bandförmige Gestalt wieder an, läuft nach vorne und inserirt sich aber nicht wie bei den Picidae an das Zungenbein, sondern, wie ich wenigstens bei Corvus glandarius und Fringilla coelebs beobachtete, welche ich näher darauf hin untersucht habe, an den oberen Kehlkopf.

Er wird im Allgemeinen dieselben Functionen als bei den Picidae ausüben.

Subcutaneus thoracicus Wiedemann. Brusthautmuskel.

Dieser Muskel entspringt bei allen von mir untersuchten Passeres von der Sehne des grossen Brustmuskels, aber nicht immer 
von der gleichen Stelle derselben. Bald kommt er von dem oberen, bald von dem unteren Ende und zwar entweder mehr von dem äusseren oder dem inneren Rande. Das Erstere ist der Fall z. B. bei Cypselus und Muscicapa, das Letztere bei Loxia und den Corvidae. Die Folge dieser verschiedenen Lage der Ursprungsstelle ist, dass der Muskel entweder eine kurze Strecke von dem Musculus pectoralis major überdeckt wird, oder neben dem hinteren Rand desselben verläuft. Während des weiteren Verlaufs aber kommt er stets iiber den schon mehrmals erwähnten Muskel zu liegen und endigt, meist ohne weitere Veränderung zu erfahren, an dem unteren Ende des „undeutlichen“ Astes der Unterflur, oder wo dieser ganz fehlt wie bei Cypselus an der ihm entsprechenden Stelle der Unterflur selbst. Nur bei Cypselus und Sturnus differenziren sich die Fasern dieses Muskels, ehe sie sich an die schon genannte Stelle inseriren, in eine Anzahl Muskelbündel.

Der Muskel behält, mit Ausnahme der eben erwähnten Fälle, auf seinem Verlaufe stets dieselbe Breite und ist nur lose an die ihn bedeckende Haut befestigt. Er wird daher auch in geringerem Masse als bei den Picidae und überhaupt den Vögeln, bei welchen er eine feste Verbindung mit der Haut eingeht, die Brusthaut falten und dadurch die in ihr sitzenden Federn sträuben.

Tensor cutis brachialis posterioris Magnus, Dermocostalis Owen. Spannerder hinteren Flughaut.

Der jetzt zu besprechende Muskel ist bei allen Passeres kräftig ausgebildet und nimmt seinen Ursprung entweder von einer oder von zwei Rippen. Das erstere ist der Fall bei Corvus glandarius, Cypselus, Sturnus, Muscicapa, Parus, Sylvia, Turdus, Alauda und Fringilla; bei ihnen entspringt er mittelst einer kurzen Sehne von der 3. oder, was häufiger ist, der 4. untersten Rippe in der Nähe der Abgangsstelle des Processus uncin atus. Von der vorderen Kante der 3. Rippe unmittelbar unter der Abgangsstelle des eben namhaft gemachten Fortsatzes kommt er bei Fringilla cannabina, von einer etwas tiefer gelegenen Stelle bei Turdus musicus, während er bei den sonst genannten Singrögeln entweder von der Aussenseite (Sturnus) oder ebenfalls von der vorderen Kante der anderen Rippe entspringt. Bei den uibrigen Corvidae nimmt er seinen Ursprung von der 3. und 4. untersten Rippe eine kleine Strecke unter der Abgangsstelle des Processus uncinatus und zwar mit dem Haupttheil der Fasern stets von der 4. Bei Corvus pica geschieht dies direct von der Aussenseite der eben genannten Rippe, während der andere kleinere Theil mit einer kurzen Sehne von einer etwas tiefer liegenden Stelle des vorderen Randes der 3. Rippe kommt. Bei Corvus cornix und corone entspringen beide Theile mittelst kurzer Sehnen in der schon bei Corvus pica beschriebenen Weise. Die Vereinigung der getrennt entspringenden Köpfe zu einem bandförmigen Muskel vollzieht sich kurz nach 
ihrer Ursprungsstelle. Die Insertion erfolgt mit dem grössten Theil der Fasern an dem unteren Ende der Schulterflur, mit den übrigen an dem ausserhalb der Schulterflur liegenden Theil der hinteren Flughaut und zwar mittelst einer Sehne wie bei allen Vögeln.

Bei den Passeres, bei denen der Muskel nur von einer Rippe entspringt, zeigt er in Bezug auf die Insertion der Fasern dasselbe Verhalten.

Der Verlauf dieses Muskels und seine Funetionen sind dieselben wie bei den übrigen Vogelordnungen.

Subcutaneus abdominalis Wiedemann. Bauchhautmuskel.

Dieser Muskel hat eine bandförmige Gestalt und entspringt stets mit einer Sehne von der vorderen Kante des unteren Theils des 0 s pubis. Ziemlich lang ist diese Sehne bei den Corvidae, kurz dagegen bei den übrigen von mir untersuchten Passeres. Auch der eigentliche Muskel zeigt nicht immer dasselbe Verhalten. Bei den Corvidae läuft er, fest mit der Aussenseite der Unterflurbälfte durch Bindegewebe verbunden, nach vorne, bis er sich mit der Gesammtmasse seiner Fasern an das untere Ende des Astes derselben inserirt. Bei den übrigen Passeres hingegen zeigt er ein ähnliches Verhalten wie bei den Grallatores. Er inserirt sich nur mit einem kleinen Theil der Fasern an den Ast der Unterflur, während die übrigen Fasern an der Aussenseite des Theils der Unterflurhälfte, der dem Abdomen und hinteren Theil der Brust aufliegt, endigen. In beiden Fällen sind die Fasern dieses Muskels nur lose an die sie bedeckende Haut befestigt.

Er wird denselben Effect bewirken wie der Muskel gleichen Namens bei den tibrigen Vögeln.

Die Zahl der Muskeln, welche sich an den einzelnen Federn inserirten, betrug fast stets 4, nur an den Federn des Halses und namentlich denjenigen, die am Mittelhals standen, fand ich manchmal 6 Muskeln.

Nachdem ich die Hautmuskeln der Picidae und Passeres geschildert habe, glaube ich, wird es am Platze sein, etwas näher auf die Angaben einzugehen, welche Magnus gerade über die Hautmuskeln dieser beiden Ordnungen in seinen „Physiologisch anatomischen Studien über die Brust- und Bauchmuskeln der Vögel" macht. Wie aus der Einleitung zu der vorliegenden Arbeit ersichtlich ist, beschreibt der genannte Forscher bei der Schilderung der Brustmuskeln der Vögel auch 2 als Hautmuskeln fungirende Bündel, die „als accessorische Muskelbündel des Pectoralis" von ihm betrachtet werden, und von welchen das eine vom Humerus, das andere vom $0 \mathrm{~s}$ coracoid entspringen und vom grossen Brustmuskel noch Verstärkungsfasern beziehen soll. Das erstere Faserbündel geht nach den Angaben von Magnu s zur Brusthaut und ist namentlich bei Picus scharf ausgeprägt, das letztere lăuft zur Armhaut und findet sich bei den Fringillen deutlich entwickelt.

Cab. Journ, f. Ornith. XXXII. Jahrg. No, 167 u. 168. Juli u. October 1884, 24 
Auf Grund meiner Untersuchungen kann ich diese Angaben nur zum Theil bestätigen. Das zuerst erwähnte Bündel, welches jedenfalls dem Subcutaneus thoracicus Wiedemann's entsprechen wird, habe ich nicht nur bei den Fringillen, sondern auch bei den Picidae und überhaupt bei allen von mir untersuchten Vögeln recht deutlich entwickelt gefunden. Allerdings entspringt es, wie aus der speciellen Schilderung dieses Hautmuskels bei den einzelnen Vogelordnungen $\mathrm{zu}$ ersehen ist, nicht immer von derselben Stelle, sondern bald vom Humerus (Picus), bald von der Sehne des grossen Brustmuskels (Fringillen), bald auch von anderen Stellen.

Das 2. Bündel dagegen, das Mag nu s bei den Fringillen beschreibt, habe ich nicht beobachtet. Dabei ist übrigens das, was derselbe über die Ursprungsweise des Tensor cutis brachialis posterioris sagt, für die meisten von mir untersuchten Vögel zutreffend. Bei einigen zeigte sich freilich ein etwas anderes Verhalten, indem der betreffende Muskel bei gewissen Singvögeln, wie solches bei der speciellen Schilderung hervorgehoben wurde, mit nur einem Kopfe an einer Rippe entsprang, während bei Buteo, wie ich an anderer Stelle ausführlicher erörtern werde, er mit 4 Köpfen von 4 Rippen seinen Ursprung nimmt.

\section{Raptatores, Raubvögel.}

Aus dieser Ordnung untersuchte ich: Buteo vulgaris, Strix brachyotus, Strix mexicanus und Athene cunicularia.

Die Angaben, welche D'Alton in der schon früher angezogenen Arbeit über die Hautmuskeln der Eulen macht, habe ich im Wesentlichen nicht blos für diese, sondern-auch für Buteo bestätigen können, dabei aber auch noch einige andere Hautmuskeln gefunden, so dass deren Zahl bei den Raubvögeln sich zusammensetzt aus dem:

Constrictor colli Owen.

Dermo-transversalis Owen.

Dermo-furcularis.

Musculus furculo-cephalicus.

Subcutaneus thoracicus Wiedemann.

Tensor cutis brachialis posterioris Magnus, oder Dermo-costalis Owen.

Dermo-iliacus Owen.

Subcutaneus abdominalis Wiedemann.

\section{Constrictor colli Owen.}

Von den zwei übereinander liegenden Schichten dieses Muskels ist nur der Subc. colli kräftig entwickelt.

Die Fasern dieser Schicht entspringen bei allen von mir untersuchten Raptatores über der äusseren Ohröffnung, zeigen aber, was die Form der Ursprungsstelle anbelangt, einige, wenn auch unbedeutende Verschiedenheiten bei den einzelnen Familien. Bei Buteo geschieht der Ursprung in der Weise, dass die dem Vorder- 
hals anliegenden Fasern am Rande der Augenhöhle anfangen, der andere Theil aber in einiger Entfernung von dieser Höhle und etwas höher vom Schädel kommt. Bei den Eulen hingegen entspringen die Fasern übereinander in einer geraden Linie, welche bei Athene der betreffenden Höhle nahe, bei Strix brachyotus und mexicanus aber etwas davon entfernt liegt. Nach ihrer Ürsprungsstelle nimmt die Schicht in allen Fällen zunächst an Breite etwas zu. Sie läuft darauf auf jeder Seite des Halses, zuerst gleich breit bleibend, dann aber etwas sich verschmälernd, in einem flachen Bogen nach hinten, um zum grössten Theil an der Unterflur, zum kleinen Theil an der Schulterflur zu endigen. An der vorderen Halshälfte kommen die Fasern dieser Schicht grösstentheils unter die Rückenflur und theilweise auch unter den Halsseitenrain zu liegen; an der hinteren Halshälfte hingegen verlaufen die Fasern in Folge ihrer schon erwähnten Convergenz in Gestalt eines bandförmigen Muskels unter dem äusseren Theil der Unterflurhälfte bis zum Ende des Halses und endigen dort zum grössten Theil an derselben. Der Rest der Fasern, aus denjenigen bestehend, welche am Hinterhals verlaufen, wendet sich dem oberen Theil der Schulterflur zu und verliert sich dort mit Ausnahme einiger Fasern, die sich in eine Sehne verwandeln und in dieser Form sich mit dem Spanner der hinteren Flughaut vereinigen.

Die auf beiden Halsseiten verlaufenden Fasern dieser Schicht treffen nur bei Strix mexicanus auf der Mittellinie der Rückenflur ungefähr in der Mitte des Halses zusammen, bei den übrigen aber sind sie durch einen mehr oder minder breiten Raum von einander getrennt. Derselbe ist an der Stelle, an welcher die Fasern die Rüickenflur erreichen, am breitesten, an der Stelle aber, an der sie die Flur verlassen, am schmälsten. Mit Ausnahme einer kurzen Strecke an ihrer Ursprungsstelle sind die Fasern der in Rede stehenden Schicht fest mit der sie bedeckenden Haut resp. der 2. Schicht Constr. colli verbunden.

Die 2. Schicht des eben genannten Muskels ist, wie schon erwähnt, nicht kräftig entwickelt. Relativ am schwächsten fand ich sie bei Buteo ausgebildet, bei welchem sie nur durch einige isolirt liegende Faserbündel, die sich am Oberhals unter der Unterflur verbreiteten, repraesentirt war. Da aber die Exemplare, welche ich untersuchte, jung waren, so ist es nicht unwahrscheinlich, dass bei alten Individuen auch diese Scheide eine ansehnlichere Entwickelung aufweist. Bei den Eulen, welche ich untersuchte, war sie stets mächtiger entwickelt als bei Buteo, doch bildete sie nur bei Strix brachyotus eine zusammenhängende Muskelscheide, welche sich unter der Haut des Halses ungefähr bis zur Theilstelle der Unterflur ausbreitete. Bei Athene und Strix mexicanus bestand sie ebenfalls wie bei Buteo aus isolirt liegenden Muskelbündeln, die aber sehr kräftig entwickelt waren. In allen Fällen nahmen die Fasern von der Mittellinie der Rückenflur ihren Anfang, liefen unter derselben wagrecht, dann aber bei Strix brachyotus unter 
schiefem, aber immer gleichem Winkel der Unterflur zu und bildeten auf der Mitte derselben eine Naht. Bei den übrigen waren die Winkel, unter denen die einzelnen Bündel von der Rücken- zur Unterflur verliefen, nicht wie bei Strix unter einander gleich, so dass die Bündel selbst dann auch natürlicherweise auf der letzteren Flur keine Naht bildeten. Auch die Fasern dieser Schicht sind fest mit der sie bedeckenden Haut und, wie schon erwähnt, fest mit dem Subcutaneus colli verbunden.

Der Constrictor colli wird, da er, was sein Verbreitungsgebiet anbelangt, sehr viel Aehnlichkeit mit dem entsprechenden Muskel der Grallatores hat, auch in ähnlicher Weise wirken.

\section{Dermo-transversalis 0 wen.}

Dieser Muskél ist schmal, bandförmig und entspringt stets mit einer kurzen Sehne; bei Strix brachyotus und mexicanus jederseits von dem schrägen Fortsatz des 4., bei Athene und Buteo von dem des 5. Halswirbels (vom Kopfe an gezählt). Von seiner Ursprungsstelle aus läuft er, ohne eine Verbindung mit der ihn bedeckenden Haut einzugehen, der Rückenflur zu und inserirt sich, etwas breiter werdend, "an die Aussenseite des Theils derselben, welcher dem Unterhals aufliegt. Er verrichtet dieselbe Function wie bei den übrigen Vögeln, bei denen er vorkommt.

\section{Der Dermo-furcularis}

ist kräftig entwickelt und kommt oberhalb des Musculus furculo-cephalicus von der Innenfläche der Furcula, bei Buteo ungefähr vom Ende des unteren, bei Strix vom Anfangstheil des oberen Drittels. Bei allen von mir untersuchten Raptatores gruppiren sich seine Fasern gleich von Anfang an zu einer Anzahl Bündel, welche mehr oder weniger dicht neben einander liegen, dem hinteren Ende der Furcula zulaufen und dann auf die Rückenflur übertreten, um sich an die Aussenseite des Theils, der dem Vorderrücken und Hinterhals aufliegt, zu inseriren. Bei Buteo und Athene breiten sich die Fasern derart unter der Haut des Unterhalses aus, dass die vordersten unmittelbar neben die hintersten des Subc. colli zu liegen hommen. Bei Strix hingegen ist ihr Verbreitungsgebiet etwas beschränkter. In allen Fällen sind die Fasern dieses Muskels, soweit sie von der äusseren Haut überdeckt werden, sehr lose an dieselbe befestigt.

Der Effect, welchen dieser Muskel erzielt, ist derselbe bei den Raubvögeln wie bei allen übrigen Vögeln.

\section{Musculus furculo-cephalicus.}

Wie bei allen Vögeln, so nimmt der in Rede stehende Muskel auch bei den Raubvögeln unterhalb des Dermo-furcularis seinen Ursprung, allerdings nicht bei allen in gleicher Weise. Bei A thene, bei der die beiden Hälften der Furcula wenig entwickelt sind und nicht zur Vereinigung gelangen, kommen die Fasern des Muskels von dem Ligament, welches sich zwischen 
Fureula und dem Os coracoid ausspannt. Bei Strix brachyotus und mexicanus dagegen entspringen die Fasern nur zum Theil von diesem Ligament, zum Theil auch von der Furcula; bei Buteo endlich fangen sie sämmtlich an dem zuletzt genannten Knochen an. Obwohl der Muskel in allen Fällen jederseits nach vorne läuft, zeigt er im Einzelnen bei den verschiedenen Familien ein verschiedenes Verhalten, das durch das Fehlen oder Auftreten des Kropfes bedingt zu sein scheint. Bei den Eulen, welchen bekanntlich ein eigentlicher Kropf fehlt, läuft derselbe ohne Gestaltsveränderung bis fast zur Theilstelle der Unterflur, worauf er breiter wird und zwar derart, dass die Fasern der beiden Muskeln die ganze Unterflur und einen Theil des Halsseitenrains überdecken und neben die Fasern des Subcutaneus colli zu liegen kommen. Mit dieser Differenzirung Hand in Hand geht eine innige Verbindung mit der sie bedeckenden Haut, also hauptsächlich mit der Unterflur, bis eine kurze Strecke unterhalb der Kehle; von dieser Stelle aus differenziren sich auf' jeder Halsseite die Fasern zu einem schmalen, bandförmigen Muskel, welcher sich bei Strix mexicanus, bei der ich den Verlauf weiter verfolgt habe, an den Körper des Zungenbeins inserirt. Bei Buteo hingegen zeigt der Muskel ein anderes Verhalten. Seine Fasern laufen wie bei den Tauben unter dem Kropf nach dem vorderen Ende der Furcula und gruppiren sich dann, so weit sie unter der Haut, welche den Kropf bedeckt, gelegen sind, in eine Anzahl Muskelbündel, die der Art divergiren, dass die äussersten, d. h. diejenigen, welche den beiden Unterflurhälften am nächsten liegen, fast gerade, die anderen dagegen einen bogenförmigen Verlauf nach vorne einschlagen. Von der Theilstelle der Unterflur an nimmt der Muskel auch dieselbe Form an und zeigt in seinem weiteren Verlauf dasselbe Verhalten wie bei den Eulen, inserirt sich jedoch nicht an das Zungenbein, sondern an den obern Kehlkopf.

Der Musculus furculo-cephalicus scheint bei allen von mir untersuchten Raubvögeln den Constrictor colli zu unterstïtzen und den Kehlkopf resp. die Zunge nach hinten zu ziehen. Bei Buteo wird er ausserdem auch noch beim Entleeren des Kropfes mit thätig sein.

Subcutaneus thoracicus Wiedemann. Brusthautmuskel.

Der jetzt zu besprechende Muskel entspringt entweder wie bei Buteo von der Sehne des grossen Brustmuskels, oder wie bei Athene und Strix mit der Hälfte der Fasern von der Sehne desjenigen Theils des Musculus biceps, welcher sich an das Os e oracoid setzt, mit der anderen Hälfte aber von der bei Buteo angegebenen Stelle. Von seiner Ursprungsstelle aus läuft er erst eine kurze Strecke neben dem hinteren Rand des grossen Brustmuskels, dann aber über ihn selbst dem Ast der Unterflur zu und inserirt sich neben dem Subcutaneus abdominalis an die Aussenseite desselben. Er bleibt auf seinem Verlaufe gleich breit und ist fest 
mit der ihn bedeckenden Haut durch Bindegewebe verbunden. Die Wirkung, die er bei den Raptatores ausübt, ist die gewöhnliche.

Tensor cutis brachialis posterioris Magnus, Dermocostalis Owen. Spanner der hinteren Flughaut.

Von allen bei den Raptatores vorkommenden Hautmuskeln zeigt der Spanner der hinteren Flughaut in Bezug auf die Art und Weise des Ursprungs bei den einzelnen Gliedern die grössten Verschiedenheiten. Bei Buteo entspringt er mit 4 Köpfen von der 3. bis 6., bei Strix brachyotus und Athene cunicularia mit 3 von der 2. bis 4. und bei Strix mexicanus mit 2 Köpfen von der 2. und 3. untersten Rippe. Der Haupttheil der Fasern kommt mit Ausnahme von Strix mexicanus bei allen von mir untersuchten Raubvögeln in der Gegend der Abgangsstelle des Proc. unc. von der 3. Rippe. Bei Buteo geschieht dies mittelst einer kurzen Sehne, welche zum Theil von der unteren Kante des eben genannten Fortsatzes, zum Theil aber von der hinteren Kante der Rippe selbst anfängt. Bei Strix brachyotus und Athene cunicularia hingegen nimmt der in Rede stehende Theil seinen Ursprung in der schon namhaft gemachten Gegend von der Aussenseite der Rippe. Bei Buteo gehen die übrigen 3 Theile direct mittelst ihrer Fasern von den übrigen Rippen in der Weise ab, dass von der 4. eine grössere Zahl Fasern als von der 5. und von dieser wieder eine grössere Zahl als von der 6. kommen. Bei Athene entspringt der der Grösse nach die 2. Stelle einnehmende Theil von der Aussenseite der 2. Rippe eine kleine Strecke unter der Abgangsstelle des Proc. un c., und der kleinste Theil von der vorderen Kante der 4. Rippe, aber noch etwas tiefer als der vorige. Bei Strix brachyotus findet gerade das umgekehrte Verhältniss statt, der kleinste Theil kommt von der 2. und der andere Theil von der 4. Rippe. Bei einem anderen Exemplar derselben Gattung fand in Bezug auf die Ursprungsweise des in Rede stehenden Muskels ein etwas anderes Verhältniss statt. Der Haupttheil der Fasern nahm in diesem Falle seinen Ursprung von der unteren Kante des Proc. unc. der 2. Rippe, die beiden anderen Theile aber der Art, dass der kleinste von der 3. und der andere von der 4. Rippe anfing. Bei Strix mexicanus endlich entspringen die Fasern dieses Muskels in gleichen Partien von der 2. und 3. untersten Rippe, unmittelbar unter der Abgangsstelle des Proc. unc. und zwar die eine Hälfte von der vorderen Kante der 2., die andere von der hinteren Kante der 3. In allen Fällen aber vereinigen sich die anfangs getrennt liegenden Köpfe in einiger Entfernung von ihren Ursprungsstellen zu einem bandförmigen Muskel, welcher immer gleich breit bleibt und dessen Fasern sich in fast gleichen Theilen an das untere Ende der Schulterflur und den ausserhalb derselben liegenden Theil der hinteren Flughaut inseriren. Die Fasern, die an der zuletzt angeführten Stelle endigen, erleiden nach ihrer Trennung von dem übrigen Theil die übliche Umwandlung in Sehnenfasern. Da der 
Dermo-costalis im Bezug auf seinen Verlauf und sein Verbreitungsgebiet bei den Raubvögeln dasselbe Verhalten zeigt wie bei den übrigen Vögeln, so wird auch seine Wirkung dieselbe sein.

Der Dermo-iliacus Owen

entspringt entweder von dem vorderen Rande des Os ilium oder dem oberen Fortsatz des letzten Brustwirbels und läuft in Gestalt eines schmalen, bandförmigen Muskels unter dem Rumpfseitenrain der Schulterfiur zu. Dort endigt er, nachdem er kurz vorher etwas breiter geworden ist, an dem unteren Ende. Er ist sowohl bei den Eulen als auch bei Buteo fest mit der ihn bedeckenden Haut verbunden. Ueber seine Functionen lässt sich dasselbe wie vom vorhergehenden Muskel sagen.

Subcutaneus abdominalis Wiedemann. Bauchhautmuskel.

Den Bauchhautmuskel fand ich bei Buteo sehr wenig, bei den Eulen hingegen etwas kräftiger entwickelt. $\mathrm{Er}$ entspringt bei allen von mir untersuchten Arten mit einer schmalen, aber ziemlich langen Sehne von der vorderen Kante des unteren Theils des Os $\mathrm{pu}$ bis und läuft, immer in gleicher Breite, neben der Aussenseite der Unterflur nach vorne bis zum Rande des Sternums. Von dieser Stelle aus wendet er sich, auf jeder Körperseite etwas breiter werdend, dem Ast der Unterflur zu und endigt mit dem grössten Theil seiner Fasern an der hinteren Seite, während ein kleiner Theil auch an die Aussenseite desselben sich inserirt. Während er an die ihn bedeckende Haut nur lose gebunden ist, ist seine Verbindung mit der Aussenseite der Unterflurhälfte eine innige. Er verrichtet bei den Raptatores dieselben Functionen wie bei den übrigen Vögeln. Die Zahl der Muskeln, welche an die einzelnen Federn sich inseriren, betrug bei allen von mir untersuchten Raubvögeln stets 4 .

\section{Rückblick.}

Nachdem die specielle Schilderung der Hautmuskeln der verschiedenen Vogelordnungen beendet ist, wird es gerathen sein, die Resultate, welche, wie ich glaube, durch die vorliegenden Untersuchungen gewonnen worden sind, in kurzen Worten zusammenzustellen. Bei allen von mir untersuchten Vögeln treten besonders differenzirte Hautmuskeln nur an einzelnen Fluren auf, nämlich nur an der Spinalflur, der Unterflur, der Schulter- und Flügelflur, hingegen fehlen sie fast immer der Oberschenkelflur und stets der Unterschenkelflur, der After- und Bürzeldrüsenflur und auch dem grössten Theil der Schwanzflur. Die Steuerfedern, die ebenfalls der letzteren Flur zugehören, müssen davon ausgenommen werden, denn sie werden bekanntlich durch die Muskeln des Steissbeins und namentlich durch den M. pubi-coccygeus und M. ischioc oc c y g e u s bewegt.

Der Grund, warum diese eben aufgezählten Fluren mit keinen 
besonderen Hautmuskeln ausgestattet sind, ist, glaube ich, theils ihrer geringen Entwicklung, theils auch in dem Umstande zu suchen, dass die Vögel in Folge ihrer Organisation dieselben leicht mit dem Schnabel erreichen und von anhaftendem Schmutz reinigen können. Der an erster Stelle geltend gemachte Grund scheint bestätigt zu werden durch die Erscheinung dass bei den Vögeln, bei welchen die Oberschenkelflur eine grössere Flächenausdehnung erlangt, auch ein besonderer Muskel auftritt, der sich zwischen ihr und einer benachbarten ausspannt. Dieser Fall tritt ein bei den Rasores und Grallatores. Auch für den anderen Theil der Ansicht, welche ich äusserte, spricht meiner Meinung nach die Thatsache, dass auch bei denjenigen Vögeln, die ihr Gefieder behufs der Reinigung oft sträuben und bei welchen der dem Becken aufliegende Theil der Rückenflur mächtig entwickelt ist, trotzdem an dieser Stelle kein besonders differenzirter Hautmuskel auftritt.

Stets stehen die Muskeln mit den Fluren, an denen sie vorkommen, in bestimmten Zusammenhang, wie dies ja von vorne herein zu erwarten war und auch an anderer Stelle schon betont wurde. Sie erleiden in den meisten Fällen dieselben Veränderungen wie die Fluren selbst. Recht deutlich fällt dies in die Augen an der Spinalflur der von mir untersuchten Passeres und Scansores. Bei beiden Ordnungen hat diese Flur, abgesehen von kleinen Lücken, welche bei den Picidae vor und hinter sowie zwischen den beiden Sattelhälften selbst auftreten, die aber für diese Betrachtungen gleichgültig sind, am Haìse und auf dem Rücken die gleiche Gestalt. Bei beiden in Rede stehenden Ordnungen findet man auch denselben Muskel und ein gleiches Verhalten desselben. So lange die Flur gleich breit bleibt, behält auch der auf jeder Seite verlaufende Muskel die gleiche Breite, sobald sie aber eine grössere Breite annimmt und sich zu dem sogenannten Sattel differenzirt, wird auch der Muskel in demselben Verhältniss breiter. Neben der Form der Fluren scheint es auch die Lebensweise zu sein, welche bei der Ausbildung der Hautmuskeln eine nicht zu unterschätzende Rolle spielt. Es zeigen nämlich die Vögel, welche ihr Gefieder am häufigsten zu reinigen haben, nicht nur die grösste Anzahl besonders differenzirter Hautmuskeln, sondern auch eine mächtige Entwickelung derselben. Besonders ist dies der Fall bei dem Dermo-transversalis und dem Subcutaneus thoracicus der Rasores. Während diese beiden Muskeln in der Regel schmal sind und mit einem Kopfe entspringen, sind sie sowohl bei Nothura als auch bei Gallus in ganz anderer Weise entwickelt. Der D er motransversalis entspringt bei dem zuerst genannten Vogel mit 8, bei Gallus mit 4 Köpfen und ausserdem ist jeder einzelne Theil relativ viel mächtiger entwickelt als bei den übrigen Vögeln. Dasselbe lässt sich auch vom Subcutaneus thoracicus sagen; er entspringt bei beiden namhaft gemachten Hühnervögeln mit 2 Köpfen und repräsentirt kein schmales Band, sondern eine breite Muskellage. 
Doch nicht nur das Sträuben des Gefieders, sondern auch andere Factoren der Lebensweise scheinen mir auf die Ausbildung der Hautmuskeln nicht ohne Einfluss zu sein. Namentlich ist es, wie schon bei der speciellen Schilderung der Hautmuskeln gelegentlich betont wurde, das Fehlen oder Auftreten des Kropfes oder der sehr erweiterungsfähigen Speiseröhre, das auf die Form und den Verlauf des einen oder anderen Muskels nicht ohne Wirkung zu bleiben scheint. Bei den Natatores, Rasores und Columbinae wird dadurch hauptsächlich der Subcutaneus colli in Mitleidenschaft gezogen. Er endigt bei diesen Gruppen nicht wie bei den Grallatores zum Theil an der Unter- und zum Theil an der Schulterflur; obgleich die Unterflur bei den Arten der genannten Ordnungen fast genau dasselbe Verhalten als bei den letzteren zeigt, sondern inserirt sich an die Furcula, so dass es ihnen möglich wird, bei der Contraction auf den Kropf einzuwirken. Noch deutlicher tritt der Einfluss, den der Kropf unter Umständen auf die Ausbildung der Hautmuskeln ausïben kam, bei den von mir untersuchten Raubvögeln, den Eulen und Bussarden, hervor. Wie schon bei der speciellen Schilderung der Hautmuskeln dieser Ordnung erörtert wurde, zeigt der Musculus furculo-cephalicus bei den letzteren ein ganz anderes erhalten als bei den Eulen. Seine Fasern gruppiren sich, soweit sie unter der Haut, welche dem Kropf aufliegt, verlaufen, in eine Anzahl isolirt liegender Muskelbündel, die, wenn sie sich contrahiren, die Haut falten und zugleich auf den Kropf einen Druck ausüben.

Natürlich wird von den Factoren, welche die Ausbildung der Hautmuskeln bedingen, bald der eine, bald der andere mehr in den Vordergrund treten, oder sie werden sich gegenseitig ergänzen. Das Letztere ist der Fall bei den Natatores, Grallatores und vor Allem bei den Rasores; indem bei ihnen sowohl die Fluren eine sehr kräftige Ausbildung besitzen als auch die Vögel sehr oft genöthigt sind, ihr Gefieder zu reinigen. Die natürliche Folge ist in der That eine ansehnliche Entwickelung der Hautmuskulatur.

Obgleich, wie schon ausführlich erörtert, bei allen von mir untersuchten Vögeln immer an denselben Fluren besonders differenzirte Hautmuskeln auftreten, so finden sich doch nicht immer dieselben Muskeln an jeder einzelnen Flur, sondern es kommt vor, dass bei den Mitgliedern einer Ordnung ein einziger Muskel unter einer Strecke der Haut sich ausbreitet, während bei einer andern Ordnung unter derselben Strecke 2 oder mehrere gesonderte Muskeln auftreten. Am auffälligsten ist dies abermals an der Rückenflur. Bei den Picidae und Passeres läuft ein Zweig des Subcutaneus c olli an der Seite der eben genannten Flur nach hinten bis zum Anfang der Beckenregion; bei den anderen Ordnungen aber erstrecken sich die Fasern des in Rede stehenden Muskels nur unter denjenigen Theil der Rückenflur, welcher hauptsächlich an der oberen Hälfte des Halses verläuft. Dagegen inserirt sich der Dermo-transversalis an die Rückenflur da, wo dieser der 
unteren Hälfte des Halses aufliegt, und bei einigen Ordnungen ein Zweig des Dermo-iliacus an denjenigen Theil, welcher dem Rücken aufliegt. Diese beiden zuletzt namhaft gemachten Muskeln übernehmen demnach mehr oder weniger die Functionen des fehlenden Zweiges des Subcutaneus colli.

$\mathrm{Ob}$ die Hautmuskulatur für die Systematik der Vögel von Bedeutung ist, getraue ich mir noch nicht zu entscheiden.

Die Resultate, die durch die vorliegenden Untersuchungeu gewonnen worden sind, glaube ich, werden am besten durch die folgenden Sätze, welche natürlich nur für die untersuchten Vögel Gültigkeit haben, ausgedrückt:

1) Die Zahl der Muskeln, welche die einzelnen Conturfedern sich inseriren, beträgt in der Regel 4.

2) Besonders differenzirte Hautmuskeln treten bei allen Vögeln an denselben Fluren auf.

3) Die Ausbildung dieser Muskeln ist abhängig von der Entwickelung der Fluren und der Lebensweise der einzelnen Arten.

4) Die Hautmuskeln können sich gegenseitig ersetzen, d. h. der eine kann in Folge seines Verbreitungsgebietes die Functionen eines anderen fehlenden übernehmen.

\section{Erklärung der Tafel.}

Schematische Darstellung der Hautmuskeln eines Schwimmvogels.

I, Unterflur.

I a, Ast der Unterflur.

II, Lendenflur.

III, Schulterflur.

IV, Rückenflur.

V, Flügelftur.

VI, Seitenhalsrain.
A, der Vogel von vorne.

B, " " " hinten.

C, " " "

VII, Rückgratrain.

VIII, Unterrain.

IX, Rumpfseitenrain.

$\mathrm{X}$, Crista sterni.

XI, Furcula.

XII, Os pubis.

XIII, Ala.

1, Subcutaneus colli.

$1 \mathrm{~b}, 2$. Schicht des Constrictor colli.

1 c, Naht der 2. Schicht des Constrictor colli.

$2 \mathrm{a}$, vorderer Theil

$2 \mathrm{~b}$, hinterer Theil $\}$ des Triangularis juguli.

$2 \mathrm{c}$, Sehne des Trinangularis juguli.

3 , Dermo-furcularis.

4, Dermo-spinalis.

5 , Subcutaneus thoracicus.

6, Dermo-iliacus.

7, Tensor cutis brachialis posterioris.

8, Subcutaneus abdominalis. 

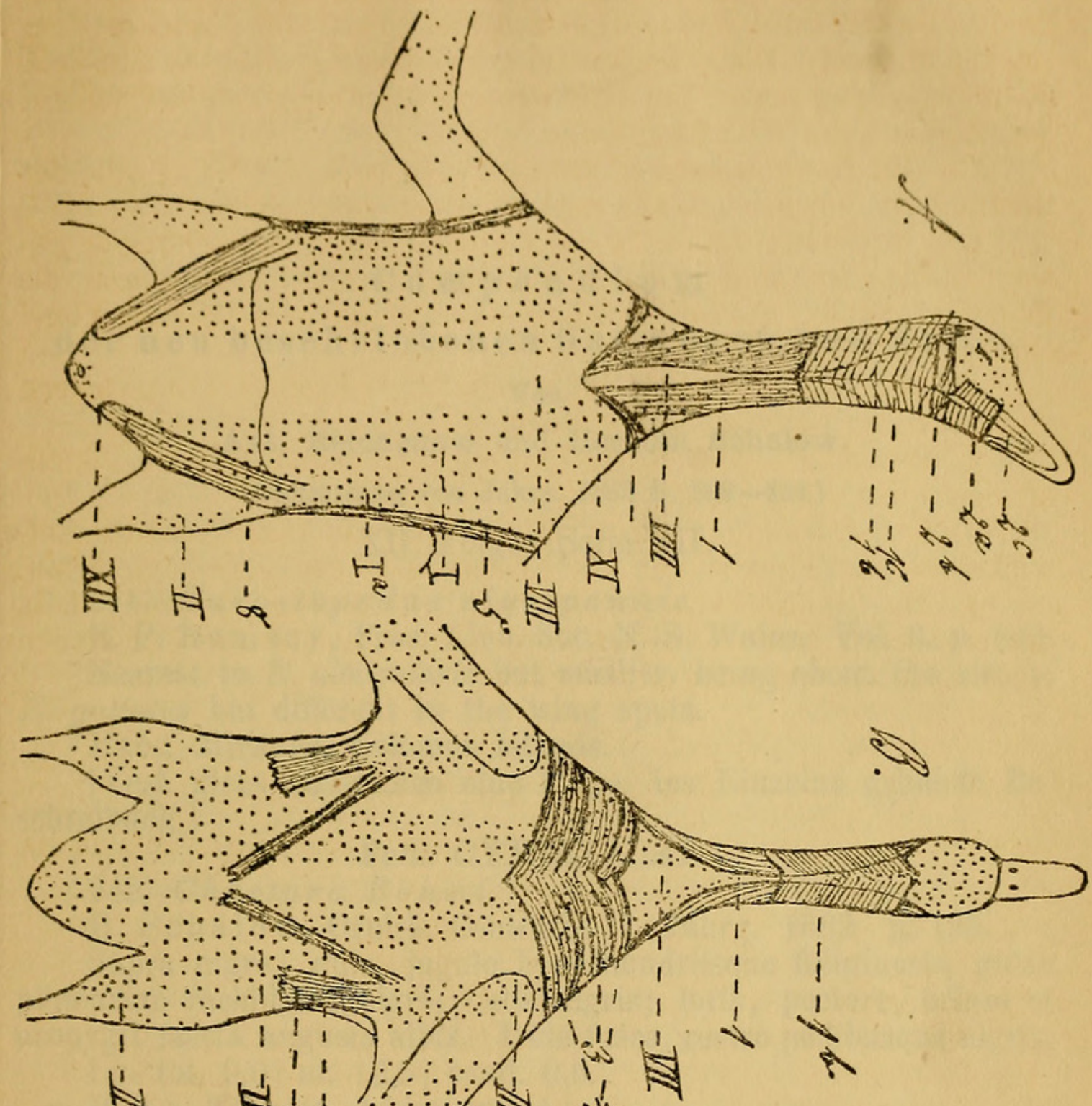

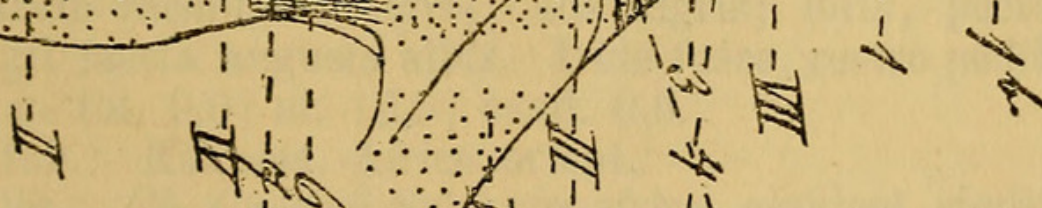

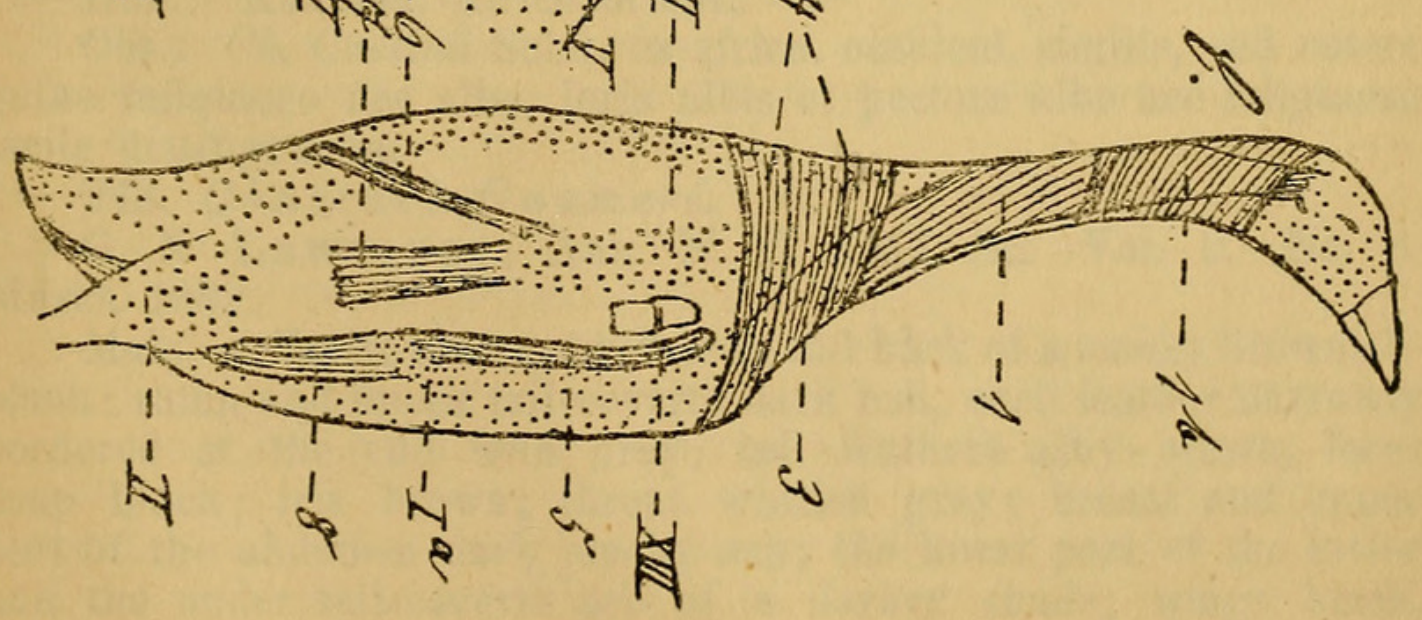




\section{$2 \mathrm{BHL}$ Biodiversity Heritage Library}

1884. "Ueber die Hautmuskeln der Vögel, ihre Beziehungen zu den Federfluren und ihre Functionen." Journal fu

r Ornithologie 32, 321-379. https://doi.org/10.1007/bf02007351.

View This Item Online: https://www.biodiversitylibrary.org/item/101693

DOI: https://doi.org/10.1007/bf02007351

Permalink: https://www.biodiversitylibrary.org/partpdf/142870

\section{Holding Institution}

Smithsonian Libraries

\section{Sponsored by}

Biodiversity Heritage Library

\section{Copyright \& Reuse}

Copyright Status: Public domain. The BHL considers that this work is no longer under copyright protection.

This document was created from content at the Biodiversity Heritage Library, the world's largest open access digital library for biodiversity literature and archives. Visit BHL at https://www.biodiversitylibrary.org. 